\title{
ON TWELVE SPECIES OF THE GENUS ACANTHOMOLGUS (COPEPODA CYCLOPOIDA: LICHOMOLGIDAE) ASSOCIATED WITH WEST INDIAN OCTOCORALS
}

\author{
by
}

\section{JAN H. STOCK}

Institute of Taxonomic Zoology (Zoölogisch Museum), University of Amsterdam, The Netherlands

\begin{abstract}
Nine new species of Acanthomolgus are described, associated with octocorals from the Netherlands' Antilles. In addition, notes on three species known already are provided. The species of the genus are subdivided into two groups, the mononyx-group which is exclusively West Indian, and the dionyx-group which is predominantly, but not exclusively, Indo-West Pacific. A key to the West Indian species is presented. Host specificity is strongly pronounced in these associates.
\end{abstract}

\section{INTRODUCTION}

The genus Acanthomolgus Humes \& Stock, 1972, comprises actually 20 species (vide: Humes \& Stock, 1973; Humes, 1973, 1974), associated with various Octocorallia (Gorgonacea, Alcyonacea, Telestacea): 15 species in the Indo-West Pacific and 5 in the West Indies.

In the present paper, 12 species of this genus are recorded from West Indian infralittoral gorgonians, including 9 new species from the Netherlands' Antilles.

The fieldwork in the Netherlands' Antilles, in $1958 / 59$ and $1973 / 74$, was supported by grants from the Netherlands' Foundation for the Advancement of Tropical Research (Foundation WOTRO, formerly WOSUNA, The Hague).

The author is indebted to the Director, scientific and technical staff of the Caribbean Marine Biological Institute, Curaçao, Netherlands' Antilles, for hospitality and generous assistance during both fieldwork periods.

Almost all gorgonian hosts were identified by Dr. Frederick M. Bayer, Institute of Marine Science, Miami, Florida; in some cases material has been identified by Mr. Tom van 't Hof, biol. drs., of the Caribbean Marine Biological Institute, Curaçao. I wish to acknowledge this valuable help.

Observations on and measurements of the complete animals have been made on specimens cleared in lactophenol. The appendages and other structural details have been drawn and measured from dissected parts, mounted in Reyne's modification of Faure's medium.

The material of both copepods and hosts has been deposited in the Zoölogisch Museum Amsterdam (ZMA).

\section{ABBREVIATIONS}

The following abbreviations are used in the descriptive part of this paper:

A p p e n d a g e s (abbreviations capitalized) from anterior to posterior:

$$
\begin{aligned}
& \text { A1 = anterior antenna } \\
& \text { A2 = posterior antenna } \\
& \text { Md. = mandible } \\
& \text { Mx1 = anterior maxilla } \\
& \mathrm{Mx2}=\text { posterior maxilla } \\
& \text { Mxp. = maxilliped } \\
& \text { P1-P4 = biramous legs } 1 \text { to } 4 \\
& \text { P5 = free article of leg } 5 \\
& \text { Fu. = caudal (furcal) ramus. } \\
& \text { coxp. = coxopodite } \\
& \text { basp. = basipodite } \\
& \text { end. = endopodite (added figures indicate the ar- } \\
& \text { exp. = exopodite }\left\{\begin{array}{l}
\text { ticle, e.g. end. } 3 \text { means article } \\
3 \text { of endopodite). }
\end{array}\right.
\end{aligned}
$$

Genus Acanthomolgus Humes \& Stock, 1972

In their revision of the family Lichomolgidae, Humes \& Stock (1973: 84) used, in a key, only one 
character to discriminate females of the genera Acanthomolgus and Meringomolgus Humes \& Stock, 1972, viz. the presence of one (Meringomolgus) or two (Acanthomolgus) terminal claws on the posterior antenna. In the text of Humes \& Stock's revision (1973: 204) several additional distinctions are enumerated.

Unfortunately, the character used in the construction of the key (one or two antennal claws) revealed to be less useful when Humes (1973) described three further species, clearly belonging to Acanthomolgus in all their features, except for the antennal armature. One of the two antennal claws was reduced in these three species to a setiform vestige. In the present paper several more species showing this condition will be described.

The rudimentary nature of the second antennal claw has been found so far in West Indian species only. In the Indo-West Pacific, two subequal antennal claws have been found in all species hitherto described. However, a minority of the West Indian species (4 out of the 14 species) also shows the two-clawed condition. Thus, this morphological differentiation is not geographically supported.

Humes (1973: 105) mentions a number of additional differences between the group of species with 2 subequal antennal claws and that with 2 very unequal elements, but apart from the fact that these differences are of a rather refined nature, a number of species (e.g. mononyx n. sp., gorgoniae Humes, 1973, triangulipes n.sp.) do not fit in.

For convenience only, I have subdivided the genus Acanthomolgus in the present paper into two species groups, the dionyx-group and the mononyxgroup, which coincide with Humes's groups, but with somewhat modified diagnoses, in which the new facts discovered during the present study are taken into consideration:

dionyx-group. - A2 $\left(q, \sigma^{2}\right)$ with 2 terminal elements, both claw-like, and the smaller one at least half the length of the larger one; P4, end.2 $\left(q, \sigma^{*}\right)$ with an almost or entirely unornamented medial margin;

mononyx-group. - Second terminal element on A2 $\left(9, \sigma^{\circ}\right)$ much reduced both in length and in diameter, assuming a seta-like shape; $\mathrm{P} 4$, end.2 $\left(q, \sigma^{7}\right)$ with a row of long cilia along the medial margin.

The members of the dionyx-group are mutually clearly differentiated into a number of clear-cut species, those of the mononyx-group form a closely coherent group of sibling species.

\section{HOST SPECIFICITY}

It emerges from the present paper that many West Indian gorgonian species have ectoparasitic (and in one case, that of $A$. mononyx, endoparasitic) Acanthomolgus species. In the great majority of cases, only one Acanthomolgus species is associated with every host (exceptions: Gorgonia ventalina and Plexaura flexuosa, each with 2 associated copepod species). As a rule, each Acanthomolgus is restricted to only one host, or at best to two related species of gorgonians (viz., A. bilobipes on 2 closely related species of the genus Antillogorgia $=$ Pseudopterogorgia; $A$. affinis on two related species of the gorgonian genus Plexaura).

\section{LIST OF THE WEST INDIAN SPECIES OF ACANTHOMOLGUS}

The following species of the genus Acanthomolgus are known from the West Indies (those marked with an asterisk are treated in the present paper; new localities are also marked with an asterisk).

\section{The dionyx-group:}

1. * A. dionyx n. sp., on Pseudopterogorgia (or Antillogorgia) americana (Gmelin, 1791), from Curaçao*.

2. *A. gorgoniae Humes, 1973, on Gorgonia ventalina Linnaeus, 1758, from Bermuda, St. Eustatius*, and Curaçan*.

3. * A.bilobipes Humes \& Stock, 1973, on Pseudopterogorgia (or Antillogorgia) acerosa (Pallas, 1766), from Jamaica, Barbados, Puerto Rico, and Curaçao*.

4. * A.triangulipes n. sp., on Gorgonia ventalina Linnaeus, 1758, from Curaçao* and St. Eustatius*.

II. The mononyx-group:

5. * A. mononyx n. sp., on Eunicea clavigera Bayer, 1961, from Curaçao*.

6. * A. seticornis n. sp., on Plexaurella dichotoma (Esper, 1791), from St. Martin*.

7. * A. aequiseta n. sp., on Muricea laxa Verrill, 1864, from Curaçao*.

8. *A. intermedius n. sp., on Eunicea laciniata Duchassaing \& Michelotti, 1860, from Curaçao*.

9. * A. affinis n. sp., on Plexaura homomalla (Esper, 1792) and on Plexaura flexuosa Lamouroux, 1821, from Curaçao* and Bermuda.

10. * A. muriceanus Humes, 1973, on Muricea atlantica Kükenthal, 1919, from Bermuda.

11. *A. longifurca n. sp., on Eunicea tourneforti Milne Edwards \& Haime, 1857, from Curaçao.

12. A. bayeri Humes, 1973, on Pseudoplexaura porosa (Houttuyn, 1772), from Bermuda.

13. * A. longidactylus n. sp., on Plexaura flexuosa Lamouroux, 1821, from Curaçao*.

14. A. verrucipes Humes, 1973, on Eunicea calyculata (Ellis \& Solander, 1786), from Bermuda.

The West Indian species of Acanthomolgus can be identified with the aid of the following key, whereas a number of salient differences are enumerated in table I. 
Table I. Comparison of some salient characters of West Indian species of the mononyx-group of the genus Acanthomolgus.

1. A2, article 2 ( $₹$, usually also in $\hat{\delta}$ ). -

$->$ twice as long as wide: intermedius, aequiseta, seticornis.

- < twice as long as wide: affinis, muriceanus, longidactylus, mononyx, bayeri, verrucipes, longifurca.

2. A2, ratio length 4th article (first figure: along inner margin, second figure: along outer margin)/claw (along axis), for both sexes. mononyx 0.84-1.20 (o) , 0.93-1.32 ( $\hat{\delta})$

bayeri $0.87-1.13$ ( $\%), 1.08-1.34$ ( $\delta$ )

verrucipes $0.95-1.21(q), 1.18-1.39(\hat{o})$

longidactylus 1.05-1.34 ( $\%$ ), 1.03-1.28 (ô)

intermedius 1.14-1.54 (\$), 1.41-1.68 ( $\hat{\delta})$

affinis $1.20-1.66(\$), 1.55-1.78$ ( $\hat{o})$

longifurca 1.22-1.55 ( $\%), 1.57-1.86(\delta)$

muriceanus $1.54-2.04(\$), 1.68-2.13(\delta)$

seticornis $1.86-2.43(\%), 2.04-2.56(\hat{\delta})$

aequiseta $1.96-2.50($ ( ) $), 1.77-2.09(\hat{\delta})$.

3. Caudal ramus, length/width ratio, for both sexes. longifurca 2.3-2.4 ( $\%$ ), 1.8 (o)

bayeri $2.2-2.3(\%), 1.5$ ( $\hat{O}$ )

mononyx 2.2 ( 9 ), $2.3-2.4$ ( $\delta$ )

affinis $2.0-2.1(\%), 1.4-1.5(\delta)$

muriceanus $2.0-2.1(\%), 1.7-1.8(\hat{\delta})$

intermedius $1.8-1.9(\$), 1.2-1.3(\hat{o})$

longidactylus 1.7-1.8 ( $\%$ ), 1.3-1.4 ( $\hat{o})$

aequiseta $1.4-1.6(\$), 1.1-1.2(\hat{\delta})$

verrucipes $1.5(q), 1.4(\delta)$

seticornis $1.3(\%), 0.9-1.0$ ( $\hat{0}$ ).

4. P5 \&, ornamentation of outer margin. -

- with large spinules $(7-10 \mu \mathrm{m})$ : affinis, muriceanus, aequiseta.

- with small spinules ( $3-4 \mu \mathrm{m})$ : intermedius, seticornis, longidactylus, bayeri, verrucipes, longifurca.

- without spinules: mononyx.

5. Terminal elements of P5 $9 .-$

- of very unequal length: affinis, muriceanus, inte:medius, longidactylus, bayeri, verrucipes, longifurca.

- of about equal length: aequiseta, seticornis, mononyx.

6. Terminal elements of P5 8 . -

- of very unequal length: bayeri, verrucipes, intermedius, aequiseta.

- of about equal length: affinis, muriceanus, seticornis, longidactylus, mononyx, longifurca.

7. P5 $\delta$, length/width ratio. -

verrucipes 5.14

intermedius 4.87

affinis 4.63

seticornis $4.0-4.5$

bayeri 4.38

aequiseta 4.00

muriceanus 3.58

longidactylus 2.90

longifurca 2.87

mononyx 2.63

\section{KEY TO THE WEST INDIAN SPECIES OF ACANTHOMOLGUS}

1a. A2 $(\%, \hat{\text { o }})$ distally with two claw-like elements, the smaller one being at least half as long as the larger one. Article 2 of endopodite of P4 $(q, \hat{o})$ almost or entirely naked on medial side. dionyx-group . . 2

b. A2 $(\hat{\imath}, \hat{\delta})$ distally with one claw-like and one setiform element, the latter almost vestigial, much smaller both in length and in diameter than the claw. Article 2 of endopodite of $\mathrm{P} 4(9,3)$ with row of long cilia on medial side. mononyx-group . . 5

2a. The two terminal antennal claws are almost equal in length and diameter . . . . . . . . . 3

b. One of the two claws is distinctly shorter and thinner than the other . . . . . . . . . . . 4

3a. Genital segment $(\%)$ in dorsal view with rounded sides. Caudal ramus $\left(\%, \delta^{\prime}\right)$ a little longer than wide. Subterminal armature of outer surface or article 4 of A2 $(\%, \delta)$ consisting of 4 minute elements. Medial spine on 1st endopodite article of $\mathrm{P} 4(\%, \delta)$ more than half the length of the 2 nd endopodite article. . . . . . . . A.gorgoniae Humes, 1973

b. Genital segment ( $\%$ ) with slight lateral "wings". Caudal ramus $(\%, \delta)$ a little wider than long. Subterminal armature of outer surface of article 4 of A2 $(q, \hat{o})$ consisting of $1 \mathrm{long}$ and 3 small setae. Medial spine on 1st endopodite artıcle of P4 $(\hat{q}, \hat{\delta})$ much less than half as long as the 2 nd endopodite article . . . A. bilobipes Humes \& Stock, 1973

4a. Free article of P5 ( $\%$ triangular in outline. Articles 1 and 2 of $A 2$ ( $\hat{o}$ ) each with a very long inner spine. - . . . . . . . . A.triangulipes n. sp.

b. Free article of P5 ( $\$$ ) with 2 rounded swellings on the inner margin, for the rest more or less cylindrical. Articles 1 and 2 of A2 ( $\hat{o}$ ) each with a short inner spine . . . . . . . A. dionyx n. sp.

5a. Lateral margin of the free article of P5 $(q, \hat{o})$ naked. Medial margin of the same article ( $\%$ ) without conspicuous expansion . . A. mononyx n.sp.

b. Lateral margin of free rticle of P5 $(q, \hat{\delta})$ armed with row(s) of spinules. Medial margin of P5 (\%) with conspicuous expansion . . . . . . . 6

6a. Article 2 of A2 $(q, \delta)$ slender (more than twice as long as wide) . . . . . . . . . . . 7

b. Article 2 of A2 $(q, \delta)$ robust (less than twice as long as wide).... . . . . . . . 9

7a. Subterminal, outer armature of article 4 of A2 $(q, \hat{\delta})$ consisting of 4 minute elements. Caudal ramus ( $\hat{o}$ ) longer than wide . . . . . . 8

b. Subterminal, outer armature of article 4 of A2 $(q, \delta)$ consisting of 1 long and 3 small elements. Caudal ramus $(\hat{\delta})$ wider than long . . . . . . - . • • • . • • • • • A. seticornis n. sp.

8a. Free article of P5 $(q, \hat{\delta})$ with conspicuous spinules on lateral margin. Terminal setae of P5 ( $\%$ ) about equal in length. Caudal ramus ( $\%$ ) with a length/ width ratio of $1.4-1.6: 1 .$. A. aequiseta $n$. sp.

b. Free article of P5 $(q, \hat{)})$ with minute spinules on lateral margin. Terminal setae of P5 ( $\%$ ) markedly unequal in length. Caudal ramus $(\%)$ with a length/ width ratio of $1.9: 1$. . . A. intermedius n. sp.

9a. Free article of P5 $(\hat{q}, \hat{o})$ with conspicuous spinules on lateral margin . . . . . . . . . . 10

b. Free article of P5 $(f, \hat{\sigma})$ with minute spinules on lateral margin ... . . . . . . 11 
10a. Length/width ratio of caudal ramus ( $\delta$ ) $1.4-1.5: 1$. Length/width ratio P5 ( $\delta$ ) $4.6: 1$. Terminal claw on A2 $(q, \hat{)})$ relatively long . . . . A. affinis $\mathbf{n}$. sp.

b. Length/width ratio caudal ramus ( $\delta$ ) $1.7-1.8: 1$. Length/width ratio P5 ( $\delta$ ) $3.6: 1$. Terminal claw on A2 $(q, \hat{\delta})$ relatively short . . . . . . . . . . . . A. muriceanus Humes, 1973

11a. Females . . . . . . . . . . . . 12

b. Males . . . . . . . . . . . . 15

12a. Caudal ramus more than twice as long as wide 13

b. Caudal ramus less than twice as long as wide 14

13a. Lateral margin of free segment of $P 5$ with less than 10 spinules; this segment is about twice as long as its greatest width. Terminal claw of A2 relatively short . . . . . . . . A. longifurca n. sp.

b. Lateral margin of free segment of P5 with more than 10 spinules; this segment is 2.6 times as long as its greatest width. Terminal claw of A2 relatively long . . . . . . . . A. bayeri Humes, 1973

14a. Article 4 of A2 longer than article 2. Outer margin of article 2 of A2 with a row of spinules. Second endopodite article of P4 with long distal spiniform processes . . . . A. longidactylus $\mathrm{n}$. sp.

b. Article 4 of A2 slightly shorter than article 2 . Outer margin of article 2 of A2 naked. Second endopodite article of P4 with short distal spiniform processes . . . . . . . A. verrucipes Humes, 1973

15a. P5 2.8-2.9 times as long as wide; its terminal elements are subequal in length . . . . . 16

b. P5 4.4-5.1 times as long as wide; its terminal elements are of unequal length . . . . . 17

16a. Terminal claw of A2 relatively short. Medioterminal spiniform process on 3rd endopodite article of P2 not excessively long . . . A. longifurca n. sp.

b. Terminal claw of A2 relatively long. Medioterminal spiniform process on 3rd endopodite article of P2 very long . . . . . . A. longidactylus n. sp.

17a. Second article of $\mathbf{A 2}$ with a few outer spinules; ratio of greatest dimensions of 4 th article of $\mathrm{A2}$ about $7.77: 1$. . . . . . . A. bayeri Humes, 1973

b. Second article of $\mathbf{A} 2$ with naked outer margin; ratio of greatest dimensions of 4th article of $\mathrm{A} 2$ about $5.64: 1$. . . . . A. verrucipes Humes, 1973

\section{DESCRIPTIVE PART}

\section{dionyx-group}

Acanthomolgus dionyx n. sp. Fig. 1.

Material examined. -

On Pseudopterogorgia americana.

Curaçao: Playa Chikitoe; 1 \& (holotype), 1 \& (allotype), 33 \&, 3 of (paratypes); depth about $4 \mathrm{~m}$; Nov. 23, 1958 (ZMA coll. no. Co. 102,559 a-c).

\section{Description. -}

F e m a le : Body (fig. 1a) length 949-1013 $\mu \mathrm{m}$ (mean, based on 5 specimens, $973 \mu \mathrm{m}$ ). Greatest width of cephalosome $441.509 \mu \mathrm{m}$ (mean $477 \mu \mathrm{m}$ ). Very similar to $A$. bilobipes (vide Humes \& Stock,
1973, and additional description in the sequel) in general shape of the body, and in the structure of the caudal rami ( $31 \mu \mathrm{m}$ wide, $26 \mu \mathrm{m}$ long), Md., Mxp., P1, P2, P3, and the genital area.

The A1 resembles that of $A$. bilobipes (see fig. $2 \mathrm{~d}$ in the present paper); the lengths of the articles, measured along the posterior margin, are 29, 109, $29,49,51,40$, and $34 \mu \mathrm{m}$. Article 1 is $60 \mu \mathrm{m}$ long along the anterior margin.

The A2 (fig. 1b) lacks spinules on the articles. Articles 1 and 2 each bear a small, inner, setiform, naked element. Article 4 bears 4 outer, subterminal, setiform elements, none very short, of which one even nearly as long as the claw. There are 2 terminal claws, one stronger and one weaker; the latter is about $2 / 3$ of the length of the "main" claw and is accompanied by a setule. Article 2 is $90 \mu \mathrm{m}$ long (along the outer margin) and has a greatest diameter of $38 \mu \mathrm{m}$. Article 4 is $79 \mu \mathrm{m}$ long (allong the outer margin), $55 \mu \mathrm{m}$ (along the inner margin), and $26 \mu \mathrm{m}$ wide. The two terminal claws are 44 and $28 \mu \mathrm{m}$ long (along their axes).

The Mxl (fig. 1d) lacks a strong medial lobe.

The Mx2 (fig. 1e) is characteristic: the main lash is medially armed with a row of teeth of which the proximal 4 teeth are small and needlelike (in the related $A$. bilobipes, the most proximal tooth is the largest, and triangular in shape). There are only 4 , widely spaced, needle-like teeth on the auxiliary lash.

The P4 exp. as in $A$. bilobipes. The end. (fig. 1i) resembles that of bilobipes in the absence of cilia on the medial margin, in the presence of long spiniform processes on article 2 , and in the bicuspidate tip of the 2 terminal spines. However, the medioterminal spine on article 1 is $40 \mu \mathrm{m}$ long, thus more than half as long as article 2 (in bilobipes: $24 \mu \mathrm{m}$, about $1 / 3$ of the length of the $2 \mathrm{nd}$ article).

P5 is $70 \times 48 \mu \mathrm{m}$ (figs. $1 \mathrm{j}$ and $1 \mathrm{k}$ ), showing up differently when observed under different angles.

M a le : Length of the body $739-803 \mu \mathrm{m}$ (mean, based on 4 specimens, $765 \mu \mathrm{m}$ ); greatest width of cephalosome 271-336 $\mu \mathrm{m}$ (mean $299 \mu \mathrm{m}$ ). Fu. 27 $\mu \mathrm{m}$ wide, $25 \mu \mathrm{m}$ long.

Lengths of the articles of the Al (along the posterior margin): $18,85,23,41,58,35$, and 30 $\mu \mathrm{m}$. Article 1 is $51 \mu \mathrm{m}$ long along the anterior margin.

The A2 (fig. 1c) bears groups or rows of spinules on the inner surface of articles 1 and 2 , on the outer margin of article 2, and on the inner margin of article 4. Inner elements on articles 1 and 2 


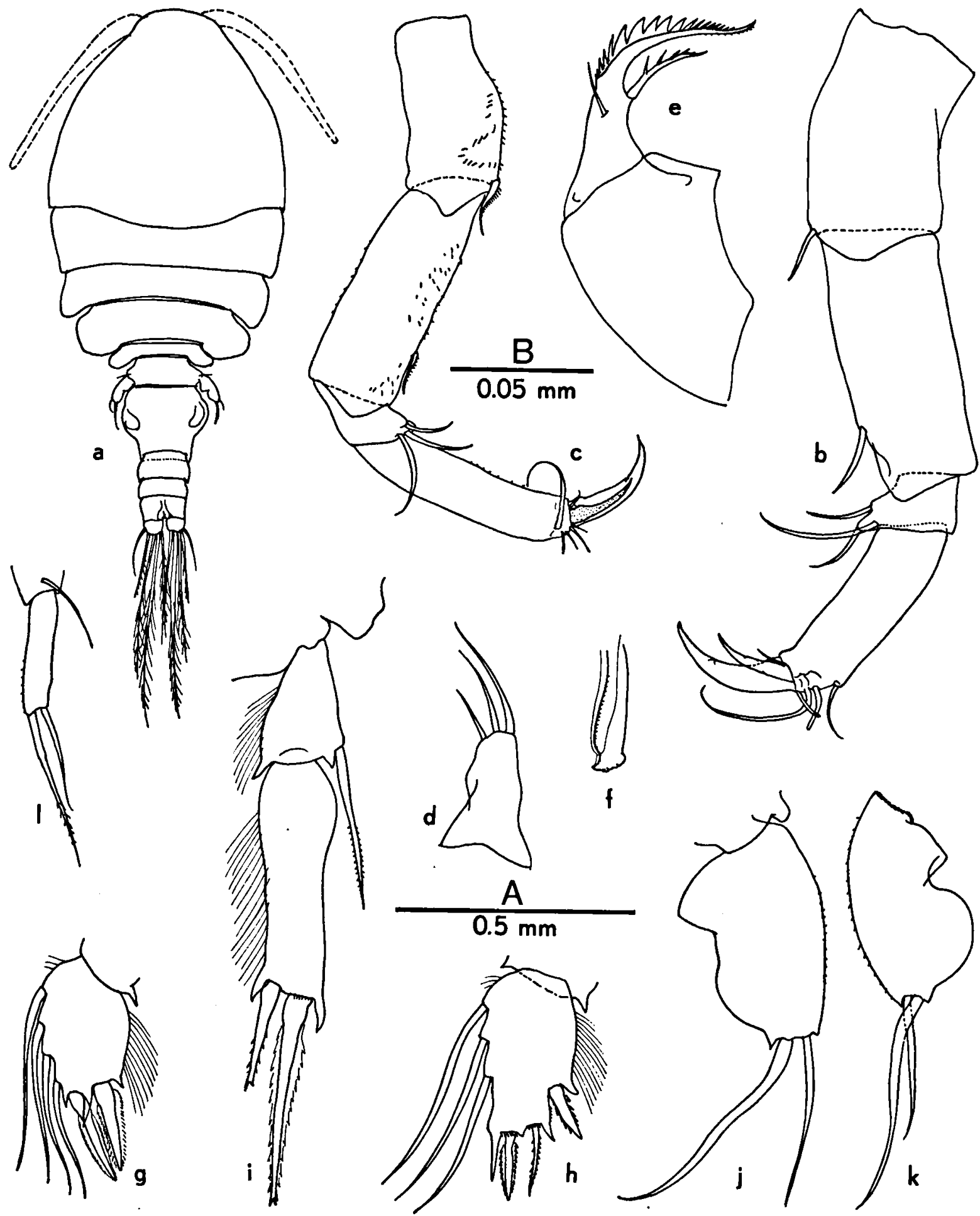

Fig. 1. Acanthomolgus dionyx n. sp. (paratypes from Cu- claw, $\hat{\sigma}$ (B); g, P1 $\delta$, end. 3 (B); h, P2 $\delta$, end. 3 (B); raçao). a, \&, dorsal (scale A); b, A2 $\$$ (B); c, A2 of (B); i, P4 $\$$, end. (B); j, P5 $q$, in situ (B); k, P5 $\$$, dissected d, Mx1 \& (B); e, Mx2 \& (B); f, distal end of Mxp. and mounted (B); l, P5 \& (B). 
short, thin, sigmoid, minutely pectinated. Length of article 2 (along the outer margin) $75 \mu \mathrm{m}$; greatest width $29 \mu \mathrm{m}$. Length of article 4 along outer margin $77 \mu \mathrm{m}$, along inner margin $59 \mu \mathrm{m}$; width $19 \mu \mathrm{m}$. Longer claw $38 \mu \mathrm{m}$, shorter claw 28 $\mu \mathrm{m}$ (along their axes).

Maxilliped claw with a rather wide distal lamella (fig. 1f).

$\mathrm{P} 1$, end. 3 (fig. $1 \mathrm{~g}$ ) with 2 , finely denticulated, spines; one spiniform process enlarged.

P2, end.3 (fig. $1 \mathrm{~h}$ ) with 1 very feeble spine; one spiniform process strongly enlarged.

$\mathrm{P} 3$ and $\mathrm{P} 4$ as in the female.

P5 (fig. 11) very slender, $40 \times 9 \mu \mathrm{m}$; some minute spinules along the outer margin.

Colour. - In live material, the female has an opaque body, dirty brown-green; the intestine and ovaries are of the same colour, though slightly more brownish; eye bright red. The male is semitransparent, greyish-orange; eye bright red.

\section{Remarks. -}

This species from Pseulopterogorgia americana is very close to $A$. bilobipes from the related host Ps. acerosa. The following clearly defined differences exist, however: (1) the two terminal claws of A2 $\left(i \sigma^{x}\right)$ are markedly unequal, both in length and in thickness, in the present species (versus almost equally long and thick in bilobipes); (2) the denticulation of the Mx2 lashes $\left(9 \sigma^{x}\right)$ is different; (3) the inner spine of P4 end.1 is much longer in the present species ( $\left.9 \sigma^{\circ}\right)$; (4) the P5 $\sigma^{\circ}$ is more slender $(40 \times 9 \mu \mathrm{m})$ in the present species than in bilobipes $(32 \times 9 \mu \mathrm{m})$; (5) the distal spiniform process on P1 end. $3 \sigma$ is longer in the present species.

Acanthomolgus bilobipes Humes \& Stock, 1973. Figs. 2-3.

\section{A. bilobipes Humes \& Stock, 1973: 96-100, figs. 53-55.}

Material examined. -

On Pseudopterogorgia acerosa.

Curaçao: Piscadera Innerbay, near former turtle hatchery; about 100 specimens, females, males and copepodids; dredge; about $3 \mathrm{~m}$; bottom: stones; Jan. 6, 1959.

Same host. Curaçao: Valentijn Bay; 6 specimens; depth about $4 \mathrm{~m}$; Dec. 2, 1958.

\section{Description. -}

Fe male: The Al (fig. 2d) is characteristic by the great elongation of the articles $2,4,5$, and 6 . The lengths of the articles (along the posterior border) is $25,111,28,56,59,51$, and $41 \mu \mathrm{m}$; article 1 , along the anterior border, is $61 \mu \mathrm{m}$ long.

The A2 (fig. 2e) has a row of 4 to 7 minute spinules on article 1. Article 2 is $75 \mu \mathrm{m}$ long (along the outer margin) and $36 \mu \mathrm{m}$ wide. Article 4 is $77 \mu \mathrm{m}$ long along the outer margin, $51 \mu \mathrm{m}$ along the inner margin, and $23 \mu \mathrm{m}$ wide. Distally, this article bears 1 very long seta (overreaching the claws) and 3 medium-long setae. The 2 terminal claws are nearly equal in length ( 28 and 29 $\mu \mathrm{m})$; one claw is slightly less thick than the other.

Mx1 (fig. 3a) with well-defined medial lobe.

Mx2 (fig. 2g): teeth on main lash gradually diminishing in size from proximal to distal; auxiliary lash with 5 slender teeth on the medial margin, and 1 slender tooth near the distal end on the lateral margin.

Mxp. (fig. 2h): endite and terminal spine subequal; setule near the base of the endite very short.

P1 (fig. 3b): distinct swelling on the lateral side of the coxp.; terminal seta on end. 3 hardly more robust than the other setae.

P3 (fig. 3e): terminal spine on end. 3 stightly longer and slightly more heavy than the other two spines.

P4 (fig. 3f): end. without cilia on medial margin; medioterminal spine on end. 1 about $1 / 3$ of the length of article 2, viz. $24 \mu \mathrm{m}$ long.

P5 (figs. 3g, h) shows up different when observed under different angles (similar to the situation found in $A$. gorgoniae, vide Humes, 1973, figs. 95, 96); the swelling of the distal part may be more or less clear. The length of P5 is 66-71 $\mu \mathrm{m}$, the greatest width (in the distal half) is $25-35$ $\omega \mathrm{m}$. The lateral margin of the article bears several rows of minute spinules.

The genital area (fig. 2b) bears 2 long, spiniform elements (one more robust than the other), but no triangular process. The genital somite (fig. $2 a$ ) is $91 \mu \mathrm{m}$ long, $143 \mu \mathrm{m}$ wide.

The Fu. (fig. 2a) is $27 \mu \mathrm{m}$ long and $29 \mu \mathrm{m}$ wide.

Male: Al with the usual 3 extra aesthetes. Lengths of the articles (along the posterior margin) $28,80,20,43,47,45$, and $35 \mu \mathrm{m}$; article 1 is 43 $\mu \mathrm{m}$ long along the anterior margin.

The A2 (fig. 2f) has rather short elements on the inner margin of articles 1 and 2; these elements are finely denticulated. Also one of the claw-like setae on article 3 is finely denticulated. Article 2 is $62 \mu \mathrm{m}$ long along the outer margin, and $26 \mu \mathrm{m}$ wide. Article 4 is $46 \mu \mathrm{m}$ long along the inner margin, $68 \mu \mathrm{m}$ along the outer margin, and $18 \mu \mathrm{m}$ wide. The claws are subequal, the longest is $25 \mu \mathrm{m}$ long along the axis. 


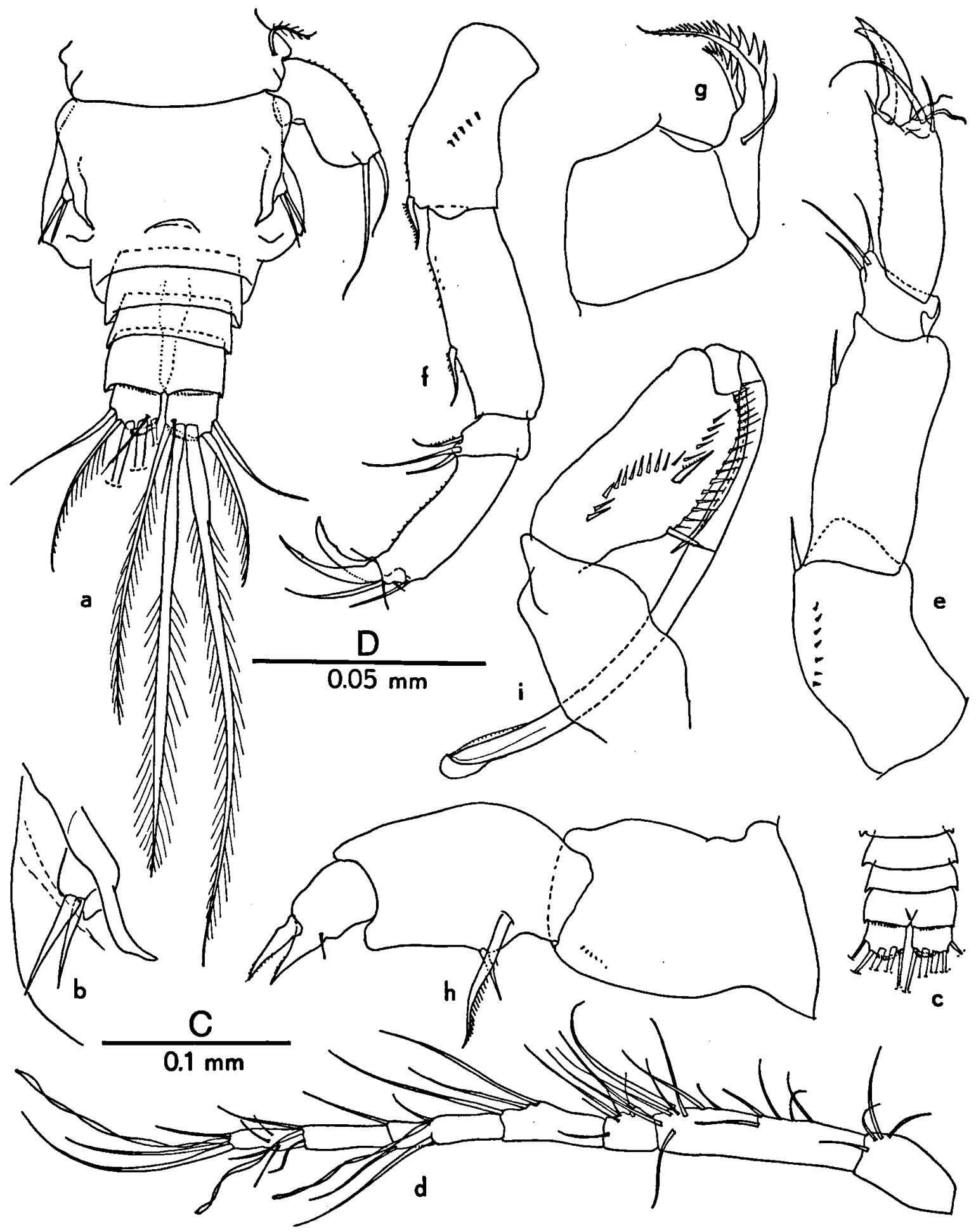

Fig. 2. Acanthomolgus bilobipes Humes \& Stock, 1973 (from Curaçao). a, urosome, + , dorsal (scale C); b, genio (C); d, A1 \& (C); e, A2 \& (B); f, A2 \& (B); g, Mx2 tal area, $\%$, dorsal (D); c, terminal portion of urosome, 


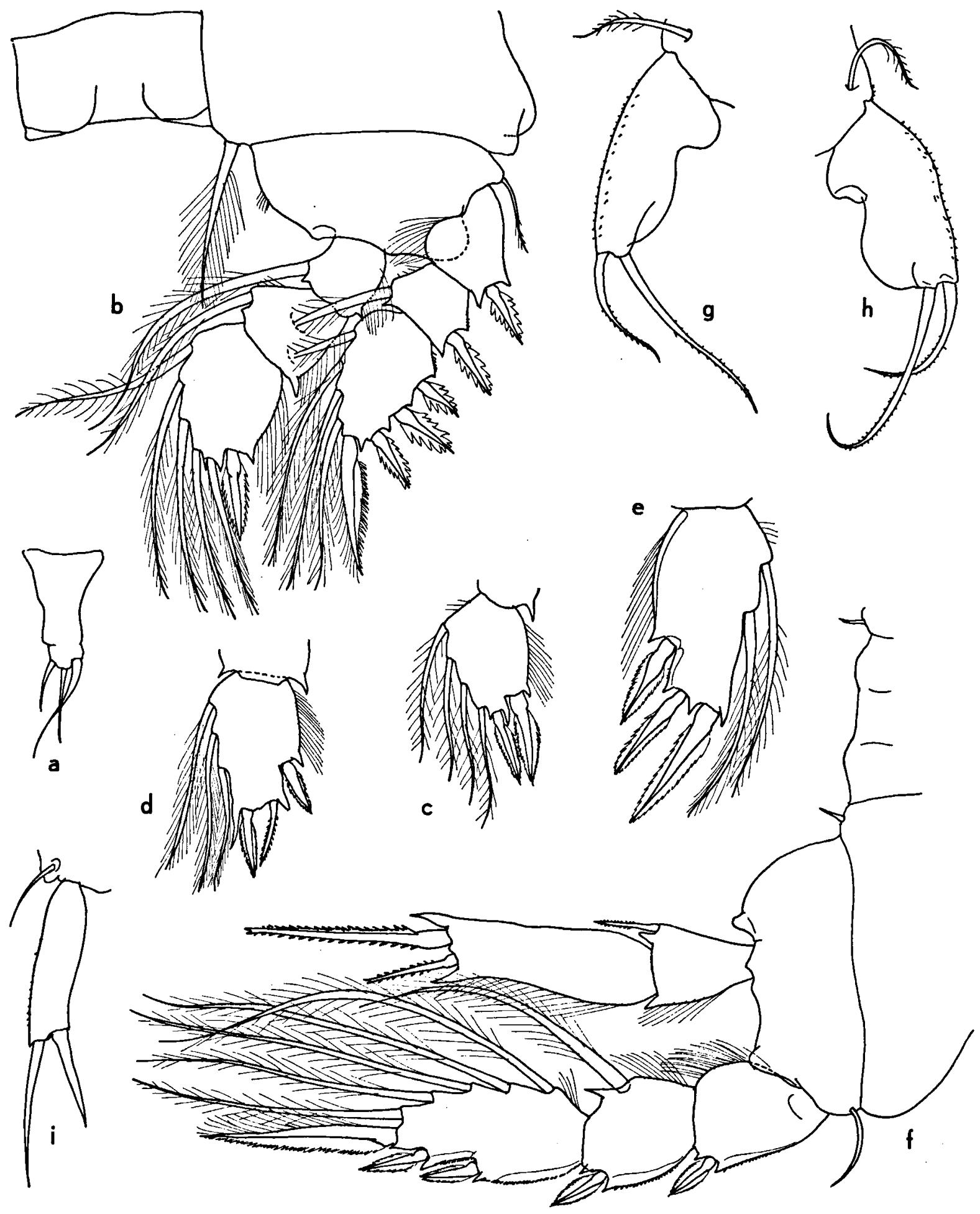

Fig. 3. Acanthomolgus bilobipes Humes \& Stock, 1973 (from Curaçao). a, Mx1 $\&$ (scale B); b, P1 \& (B); c, P1 $\hat{o}$, end. 3 (B); d, P2 $\hat{o}$, end. 3 (B); e, P3 $\$$, end. 3

(B); f, P4 ㅇ (B); g, h, P5 $\&$, in different views (B); i, P5 of (D). 
Mxp. (fig. 2i) with 2 rows of spines, mutually of rather uniform size. Terminal claw with prominent terminal lamella.

P1 (fig. 3c): end. 3 with 2 finely denticulated spines; terminal spiniform process slightly enlarged.

P2 (fig. 3d): medial spiniform process on end. 3 extremely elongated; the lateroterminal spine is weakly developed.

$\mathrm{P} 3$ and $\mathrm{P} 4$ as in the female.

P5 (fig. 3i) $32 \times 9 \mu \mathrm{m}$; laterally with minute spinules.

Fu. $22 \mu \mathrm{m}$ wide, $18 \mu \mathrm{m}$ long.

Colour of live specimens. - Body semitransparent, dirty white; eye large, bright red.

\section{Remarks. -}

This species has been extensively described in the monograph of Humes \& Stock (1973). In the original description, some doubt was expressed about the host of $A$. bilobipes, but the present Curaçao records prove beyond doubt that the supposition was right that Pseudopterogorgia (or Antillogorgia) acerosa is the actual host.

A number of new illustrations and some short descriptive notes on the Curaçao specimens are provided here, chiefly to supplement the original description, and to demonstrate the differences with the closely related $A$. dionyx, described in the preceding pages, discovered on a closely related host (Pseudopterogorgia americana). Features not mentioned or illustrated here for bilobipes are in full agreement with the data in the original description.

\section{Acanthomolgus gorgoniae Humes, 1973}

A. gorgoniae Humes, 1973: 105-112, figs. 81-104.

Material examined. -

All from Gorgonia ventalina.

Curaçao: Blauw Bay; 10 specimens; depth about $3 \mathrm{~m}$; Oct. 17, 1958.

Curaçao: Santa Barbara; about 100 specimens; depth about $3 \mathrm{~m}$; Nov. 3, 1958.

St. Eustatius: Gallows Bay; 39 specimens; depth about 2 m; Feb. 11, 1959.

Remarks. -

This species was already known from the same host in Bermuda.

\section{Acanthomolgus triangulipes n. sp. Figs. 4-5.}

Material examined. -

All from Gorgonia ventalina.

Curaçao: Santa Barbara; 1 \& (holotype), 5 \& (para- types); depth about $3 \mathrm{~m}$; Nov. 3, 1958 (ZMA coll. no. Co. $102,562 \mathrm{a}-\mathrm{c})$.

St. Eustatius: Gallows Bay; 1 of (allotype), 3 \%; depth about 2 m; Feb. 11, 1959 (ZMA coll. no. Co. 102,573b).

Curaçao: Blauw Bay; 1 \%; depth about $3 \mathrm{~m}$; Oct. 17, 1958.

Moreover $1 \&$ from St. Martin, Little Bay; about $3 \mathrm{~m}$ depth; Feb. 7, 1959; in a residue from mixed gorgonians, chiefly Plexaurella dichotoma.

Description. -

Fem a le: Body (fig. 4a) 914-1036 $\mu \mathrm{m}$ long (mean, based on 4 specimens, $965 \mu \mathrm{m}$ ); greatest width of cephalosome 508-539 $\mu \mathrm{m}$ (mean $524 \mu \mathrm{m}$ ). Metasomites bearing legs 2 and especially 3 with well-developed epimeral areas. The somite bearing P5 is $161 \mu \mathrm{m}$ wide and $86 \mu \mathrm{m}$ long. The genital somite (fig. 4b) is $145 \mu \mathrm{m}$ long and $174 \mu \mathrm{m}$ wide. Genital area (fig. 4f) distinctive: the 2 setae on the caudal solerite found in other species of the genus are replaced by 2 obtuse, finger-shaped cuticular elements; a triangular process separates these 2 elements. The medial sclerite ends caudally in a sharp point. Fu. (fig. 4d) $34 \mu \mathrm{m}$ long and $30 \mu \mathrm{m}$ wide, shorter than the anal somite. The longest two furcal setae are plumose, the others are naked. The dorsal seta is skightly longer than the width of the ramus.

The A1 resembles that of $A$. mononyx (cf. fig. $6 \mathrm{~g}$ in this paper). The lengths of the articles, measured along the posterior margin, are: 50,108 , $25,49,44,40$, and $26 \mu \mathrm{m}$. Article 1 is $63 \mu \mathrm{m}$ long along its anterior margin.

The A2 (fig. 4g) has about 6 stiout spinules on the basal article. Article 2 is $62 \mu \mathrm{m}$ long (along the outer margin) and $51 \mu \mathrm{m}$ wide; its outer margin bears a row of conspicuous spinules. Article 3 bears 3 setae, of which 1 is long, the other 2 are short. Article 4 is $106 \mu \mathrm{m}$ long along its outer mangin, $73 \mu \mathrm{m}$ along its inner margin, and $25 \mu \mathrm{m}$ wide. Its terminal portion bears the usual 4 outer elements; however, only 1 of these is setiform, the other 3 are finger-shaped, spinule-tipped, elements. At the base of the claw, there are 2 elements, one short, the other more than half as long as the claw. The longer of these two elements is much thinner than the claw, but stronger than a seta. Length of the (main) claw $51 \mu \mathrm{m}$ (along its axis).

The Md. is like that of $A$. muriceanus (cf. Humes, 1973, fig. 10).

The $\mathrm{Mx} 1$ (fig. 5a) bears 2 longer and 1 shorter terminal element, and a posteriorly directed lobe.

The $\mathrm{Mx} 2$ (fig. 5b) has an unarmed basal article; the main lash is armed medially with triangular teeth; the auxiliary lash has needle-shaped teeth 


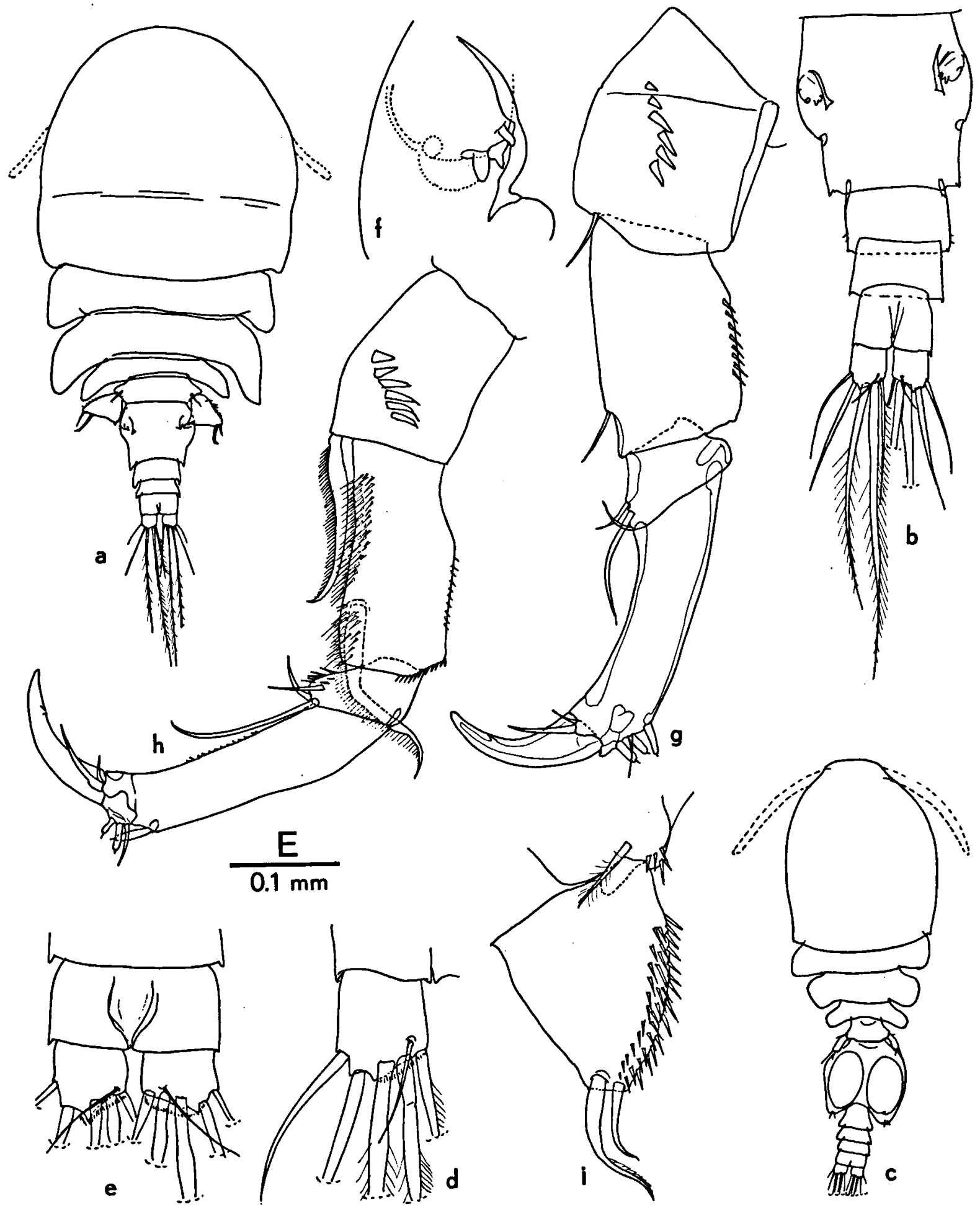

Fig. 4. Acanthomolgus triangulipes n. sp. ( $\%$ paratype from Curaçao, of allotype from St. Eustatius). a, $q$, dorsal (scale A); b, urosome, $\uparrow$, dorsal (E); c, $\hat{\delta}$, dorsal

(A); d, Fu. $\$$, dorsal (B); e, anal somite and Fu. $\delta$, dorsal (B); f, genital area, $\%$, dorsal (D); g, A2 \& (B); h, A2 ơ (B); i, P5 \& (B). 
on both margins; a pencil-shaped element is present at the base of the main lash; medioproximally, the 2 nd article bears a small process instead of a setule.

Mxp. (fig. 5d) of the usual structure. The distal spine is about as long as the distal endite; the subdistal seta is very short, almost rudimentary.

P1 (fig. 5f) has a very strongly marked, roundedly triangular, swelling at the lateral side of the coxp. The lateral basp. seta is short but plumose. The lateral exp. spines are coarsely toothed at their cranial margin, finely toothed at their caudal margin. End. 3 bears 1 finely toothed spine, 4 "normal" (= feathered) setae, and a terminal plumose seta that is slightly transformed in that it has a swollen basal third.

P2 and P3 show great similarity to those of $A$. muriceanus (cf. Humes, 1973, figs. 16 and 18).

P4 exp. as in muriceanus, but the end. (fig. 5h) is different in lacking cilia along the medial margin of article 2 and in the very strong development of the medial spine on article 1; this spine is about $3 / 4$ of the length of article 2 , inconspicuously barbed, and shows a swelling on its lateral margin slightly proximad of the middle. There is not so great a size difference in the lengths of the 2 terminal end. spines as in most other species. The median coxp. element in P4 is finger-shaped with a narrower tip.

P5 (fig. 4i) is most characteristic: it has a triangular outline, is $83 \mu \mathrm{m}$ long and $67 \mu \mathrm{m}$ wide, the apex of the triangle pointing in medial and caudal direction. At the base of the article, a shont plumose seta is implanted. The lateral margin of the article bears several (at least 3 ) rows of densely packed, $7 \mu \mathrm{m}$ long, spinules. There are 2 distal elements, the lateralmost of which is much shorter than the innermost.

Ma le: Only a single male (fig. 4c) has been found. It is $896 \mu \mathrm{m}$ long, the greatest width of the cephalosome is $341 \mu \mathrm{m}$. The genital somite is 174 $\mu \mathrm{m}$ wide and $160 \mu \mathrm{m}$ long. The Fu. (fig. 4e) is 22 $\mu \mathrm{m}$ long and $24 \mu \mathrm{m}$ wide; all furcal setae are broken.

Al with the usual 3 extra aesthetes. Lengths of the articles (measured along the posterior margin) are: $31,74,17,37,40,33,27 \mu \mathrm{m}$. Article 1 is 52 $\mu \mathrm{m}$ long along the anterior margin.

A2 (fig. 4h) with very elongated, spiniform, sigmoid, pectinated elements on the inner margin of articles 1 and 2. Article 2 is $73 \mu \mathrm{m}$ long (along the outer margin), and $38 \mu \mathrm{m}$ wide; a row of fine spinules is present on the outer margin and on the distal margin; the inner surface is oovered by 2 , nearly confluent, fields of densely packed spinules. Article 3 bears 1 long and 2 short setae, all naked; moreover, the inner surface of this article bears a group of spinules. Article 4 is $104 \mu \mathrm{m}$ long (along the outer margin), $71 \mu \mathrm{m}$ long (along the inner margin), and $22 \mu \mathrm{m}$ wide; the inner margin bears a row of minute spinules; distal armature as in the female. Terminal claw $60 \mu \mathrm{m}$ long (along its axis).

Md. and Mxl as in the female.

Mx2 (fig. 5c) with a group of cilia on the medial side of the basal anticle; such a group of cilia lacks in the female.

Mxp. (fig. 5e) of the general structure usual in this genus; article 2 very slender, with 2 spines (the longest of which is unilaterally barbed) and with 2 rows of conspicuous spinules, one row starting near the shortest spine, the other row starting at the very base of the article; the spinules of the latter row rapidly increase in length from proximal in distal direction, then diminish in size, then increase in size again, whereas they are rather short near the distal end of the row.

P1: exp., coxp., basp. and intercoxal plate as in the female; all end. articles (fig. $5 \mathrm{~g}$ ) show sexual dimorphism in that they are more elongate and more rectangular in shape than in the female. The transformed terminal sota of end. 3 ( $q$ ) is replaced by a strong, inwardly curved spine in the $\sigma^{7}$; this spine is almost smooth on the lateral margin, denticulated on the medial margin.

P2, P3, and P4 without sexual dimorphism.

P5 (fig. 5i) 34-35 $\mu \mathrm{m}$ long, 10-12 $\mu \mathrm{m}$ wide. Distal part of the lateral margin with some 5 spinules. Distally, 2 very unequal elements arise, the shortest of which on the medial side.

Colour of live specimens. - Body opaque, yellowish or slightly greyish; ovaries and eggs yellowish to grey-green. Eye pale red.

\section{Remarks. -}

This species lives on the same host, Gorgonia ventalina, as Acanthomolgus gorgoniae, but is much less numerous. In the morphology of the appendages, the present species differs widely from $A$. gorgoniae, and as a matter of fact from all other members of the genus as well. The triangular P5 $q$ is most distinctive (the proposed specific name, triangulipes, refers to this character). Other peculiarities are the nature of the sexual dimorphism in the A2 and in the P1 end., the unequality 


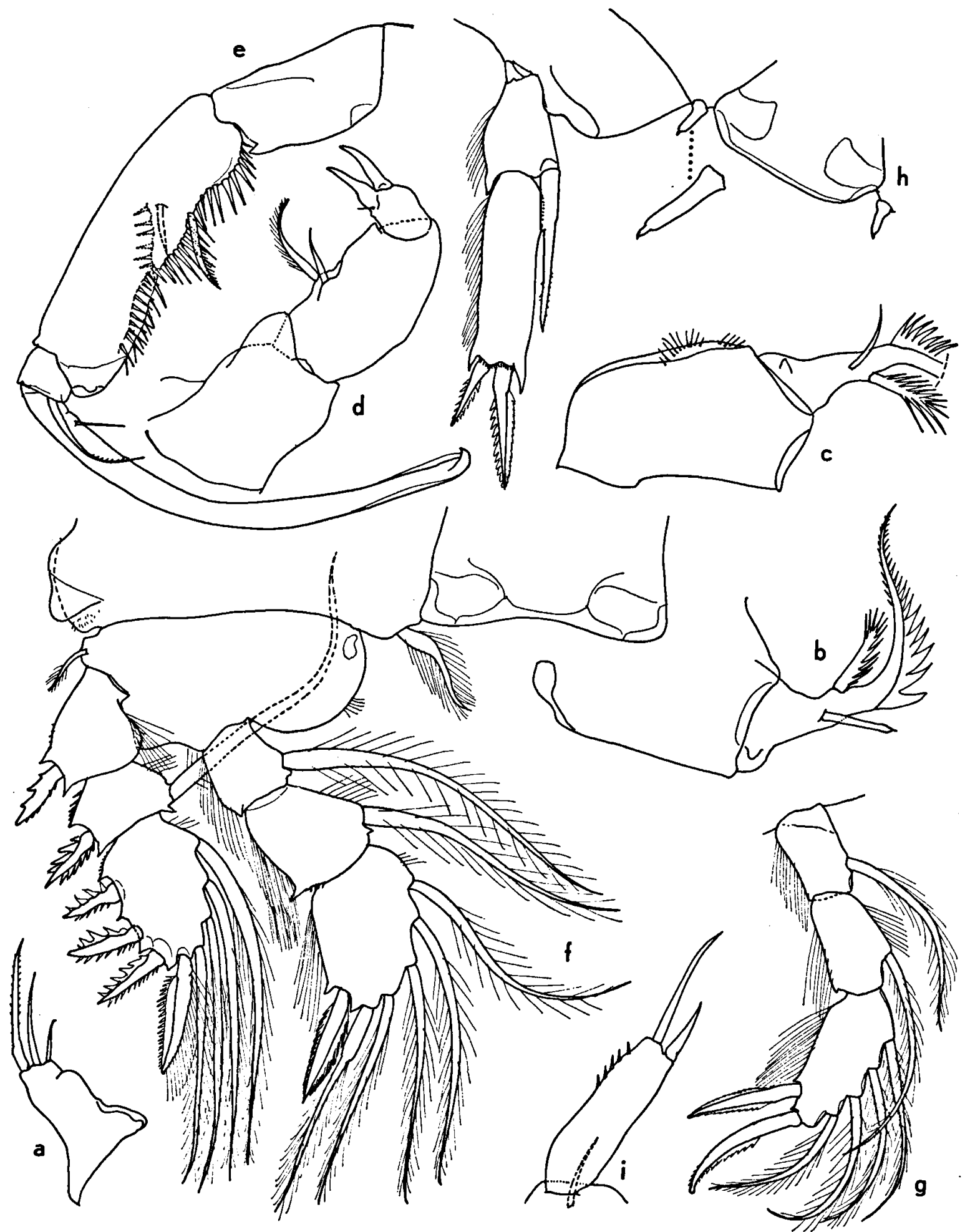

Fig. 5. Acanthomolgus triangulipes n. sp. ( 9 paratype from Curaçao, of allotype from St. Eustatius). a, Mx1 $q$ (scale B); b, Mx2 \& (B); c, Mx2 ô (B); d, Mxp. क

(B); e, Mxp. \& (C); f, P1 \& (B); g, P1 f, end. (B); h, $\mathrm{P4} \&$, end. and intercoxal plate (B); $i, P 5$ o (D). 
of the distal setae of P5 $\sigma^{x}$, the short Fu. ( $\left.9 \sigma^{x}\right)$, the protruding epimeral areas of the metasome ( $q$ ), the difference in ornamentation of the cranial and caudal side of the exopodite spines in P1 $\left(q 0^{x}\right)$, the presence of cilia on the basal anticle of Mx2 $\sigma^{*}$, the great length of the medial spine on P4 end. $1\left(90^{7}\right)$, and the replacement of seti- or spiniform elements by finger-shaped ones in the genital area ( $q$ ).

Special attention should be drawn to the A2 claws, which are kind of intermediate between the dionyx and mononyx situation. There are two distal elements, the shorter of which is more than half as long as the longer (a dionyx feature), but at the same time, the shorter element is much weaker than the longer one (a mononyx feature). Since in all species of the mononyx-group, the shorter element is still much more reduced (to the point of becoming almost vestigial), and since the ciliation of the P4 end. provides an additional support, I consider $\boldsymbol{A}$. triangulipes as a member of the dionyx-group, but admit at the same time that it is a highly original species, not closely related to any known member of the genus.

\section{monon yx - g r o u p}

Acanthomolgus mononyx n. sp. Figs. 6-8.

\author{
Material examined. - \\ All parasitic in the octocoral Eunicea clavigera. \\ Curaçao, about $500 \mathrm{~m} \mathrm{~W}$. of Piscadera: 1 (holotype), \\ 1 \& (allotype), $7 \%$ and 3 i (paratypes), from 34-40 m \\ depth, March 29, 1974 (ZMA coll. no. Co. 102,563 a-c); \\ 1 i from 22-24 m depth, Apr. 2, 1974; 5 \&, 3 of, 3 \\ copepodids from $41 \mathrm{~m}$ depth, March 26, 1974.
}

Description. -

F e m a le : Length (without furcal setae) 1001. $1185 \mu \mathrm{m}$ (mean, based on 6 specimens, $1104 \mu \mathrm{m}$ ); greatest width of cephalosome 618-744 $\mu \mathrm{m}$ (mean $679 \mu \mathrm{m}$ ). The body (fig. 6a) has a strongly widened prosome. The epimeral areas of metasomites 1 to 3 are rounded, and rather strongly projecting. Metasomite 4 is small and partly hidden under the tergum of somite 3. The first urosomite is 133$145 \mu \mathrm{m}$ wide. The genital somite (fig. $6 \mathrm{~b}$ ) is 176$193 \mu \mathrm{m}$ wide and 153-170 $\mu \mathrm{m}$ long; the anterior part of the somite is expanded; the narrower posterior part is separated by a shallow notch from the anterior part. Each genital area (fig. 6d) beans 2 naked, spiniform elements, inserted on a low pedicel; no lamelliform processes mediad of the genital orifices. The 3 postgenital somites are un- adorned. The Fu. is 67-69 $\mu \mathrm{m}$ long, and 30-32 $\mu \mathrm{m}$ wide. The lateral seta arises at a slight distance from the tip of the ramus. The dorsal seta is implanted just over the base of the 2 longer terminal setae. All furcal setae are naked.

A broad, rounded rostral fold is present. The Al (fig. $6 \mathrm{~g}$ ) consists of 7 articles, which have the following lengths (measured along the posterior margin): $28,90,23,46,46,32$, and $26 \mu \mathrm{m}$, respectively. The formula for the armature is 4,14 , 6, 3, $4+1$ aest., $2+1$ aest., $7+1$ aest.; all setae are naked.

The A2 (fig. 6e) is robust, 4-segmented. Articles 1 and 2 each bear a short, thin, inner seta. The trapezoidal 3rd article bears 1 longer and 2 shortor setae. Article 4 bears on the outer margin, in subterminal position, 3 minute setules and a triangular spinule; in terminal position, 2 small, setiform elements arise. Claw strong, slightly longer than article 4, strongly curved. Article 2 is $66 \mu \mathrm{m}$ long (along the outer margin) and $48 \mu \mathrm{m}$ wide. Article 4 is $66 \mu \mathrm{m}$ long along the outer margin, $46 \mu \mathrm{m}$ along the inner margin, and $24 \mu \mathrm{m}$ wide; the terminal claw is $55 \mu \mathrm{m}$ long along its axis.

Md. (fig. $6 \mathrm{~h}$ ) of the usual type for the genus.

Mxl (fig. 6h) bearing 1 shorter and 2 somewhat longer distal setae, all naked.

The Mx2 (fig. 7a) has an unarmed basal article, and a distal article produced into an apical lash bearing medially a row of about 27 elongately pointed teeth, laterally some 7 minute, widely spaced denticles. The auxiliary lash bears medially 9 very long (spiniform) teeth; in the distal part of the lateral side it bears 4 spiniform teeth. The distal anticle bears moreover a minute proximal setule and, more distad, a strong spine.

The Mxp. (fig. 7b) has some spinules, arranged in 3 groups, on its basal article; article 2 bears 2 very unequal setiform elements; the 3 rd article is slightly cheliform at the tip, through the opposition of a triangular distal process (endite), a short triangular spine, and a seta.

P1 through P4 (figs. 7c, 7e, 7g, 8b) have the segmentation and chaetotaxis that are characteristic for the genus. The lateral exp. spines are coarsely serrated, especially in P1 to P3. The lateral basp. seta is plumose in $\mathrm{P} 1$ to $\mathrm{P} 3$, naked in P4. The medial coxp. seta is heavy, well-developed, and plumose in P1 to P3, reduced to a vestigial naked setule in P4. The intercoxal plates are roughly rectangular in $\mathrm{P} 1$ to $\mathrm{P} 3$, trapezoidal and narrower in P4. On P4 end. 1 a spiniform mediodistal element is found, which is (though spiniform) provided with short plumosities like a 

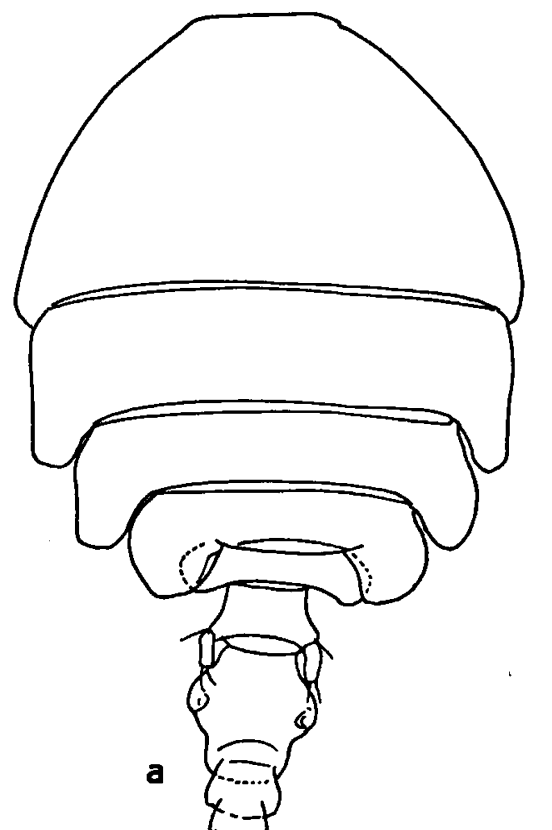

a
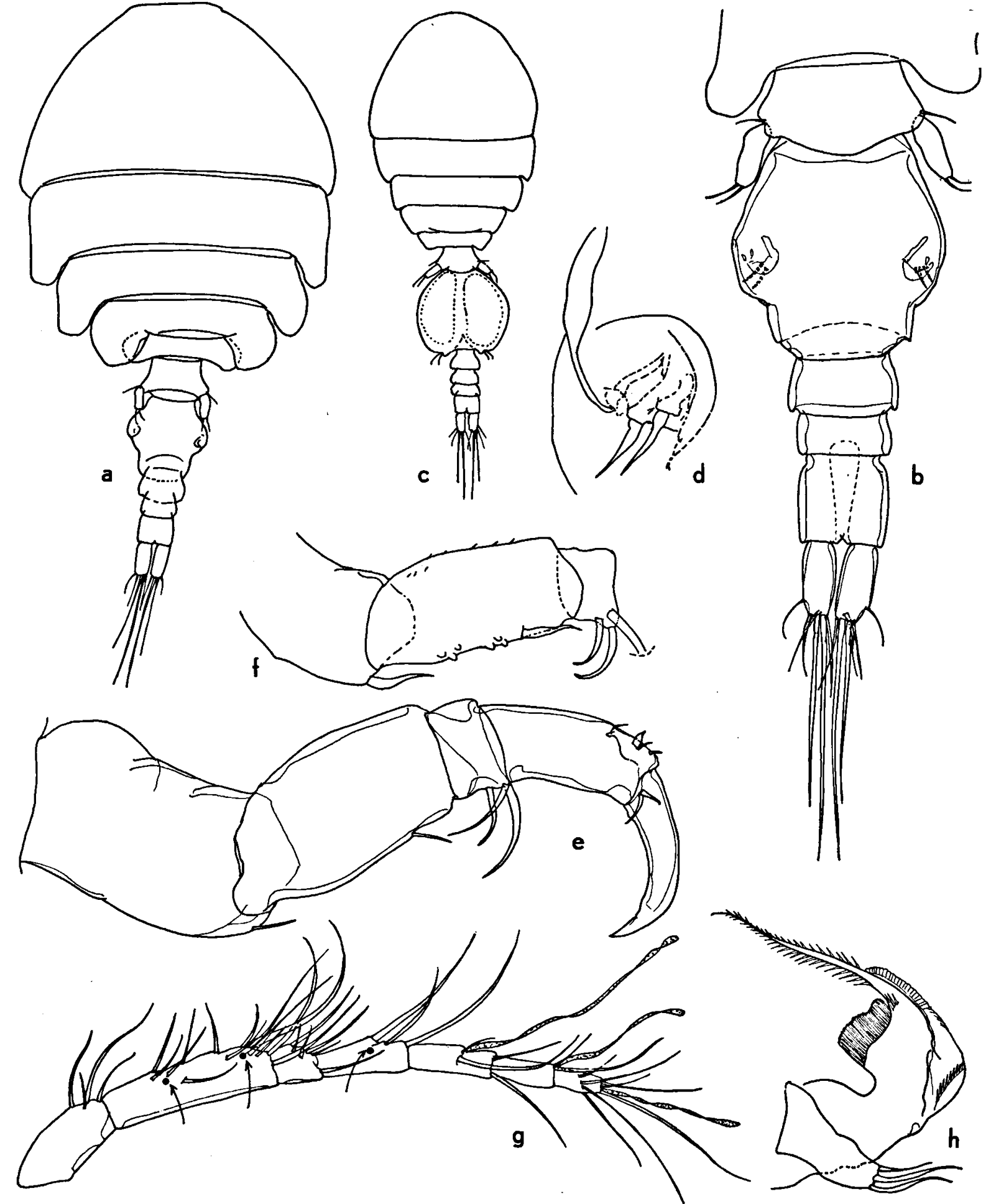

Fig. 6. Acanthomolgus mononyx n. sp. (paratypes from Curaçao). a, $\&$, dorsal (scale $A$ ); b, urosome, $\&$, ventral (E); c, ô, dorsal (A); d, genital area, \&, dorsal (D); e,
A2 \& (B); f, proximal part of A2 \& (B); $g, A 1 ~ \&$ (C), the three black dots indicate the places where extra aesthetes are implanted in $\hat{o} ; \mathrm{h}, \mathbf{M d}$. and $\mathrm{Mx} 1, q$ (B). 

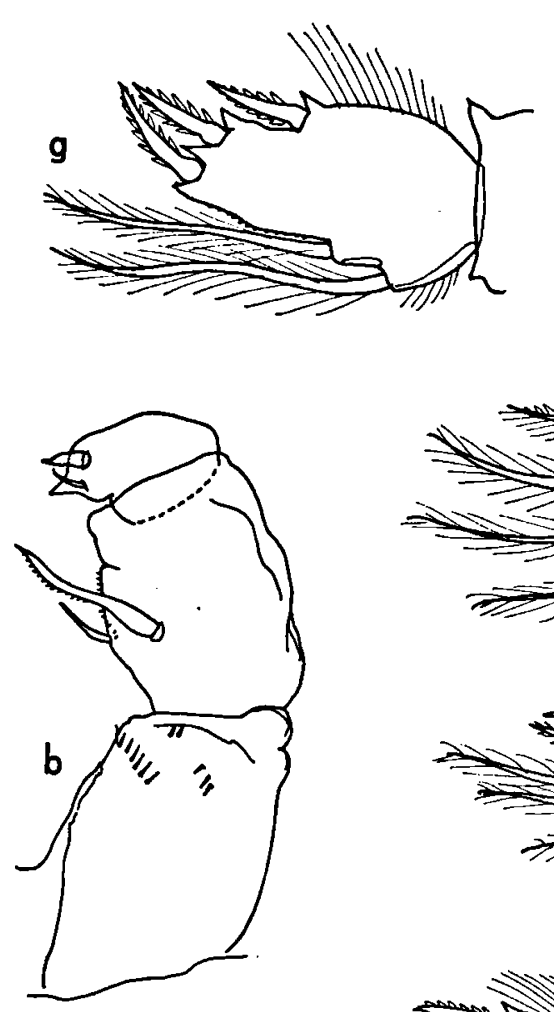


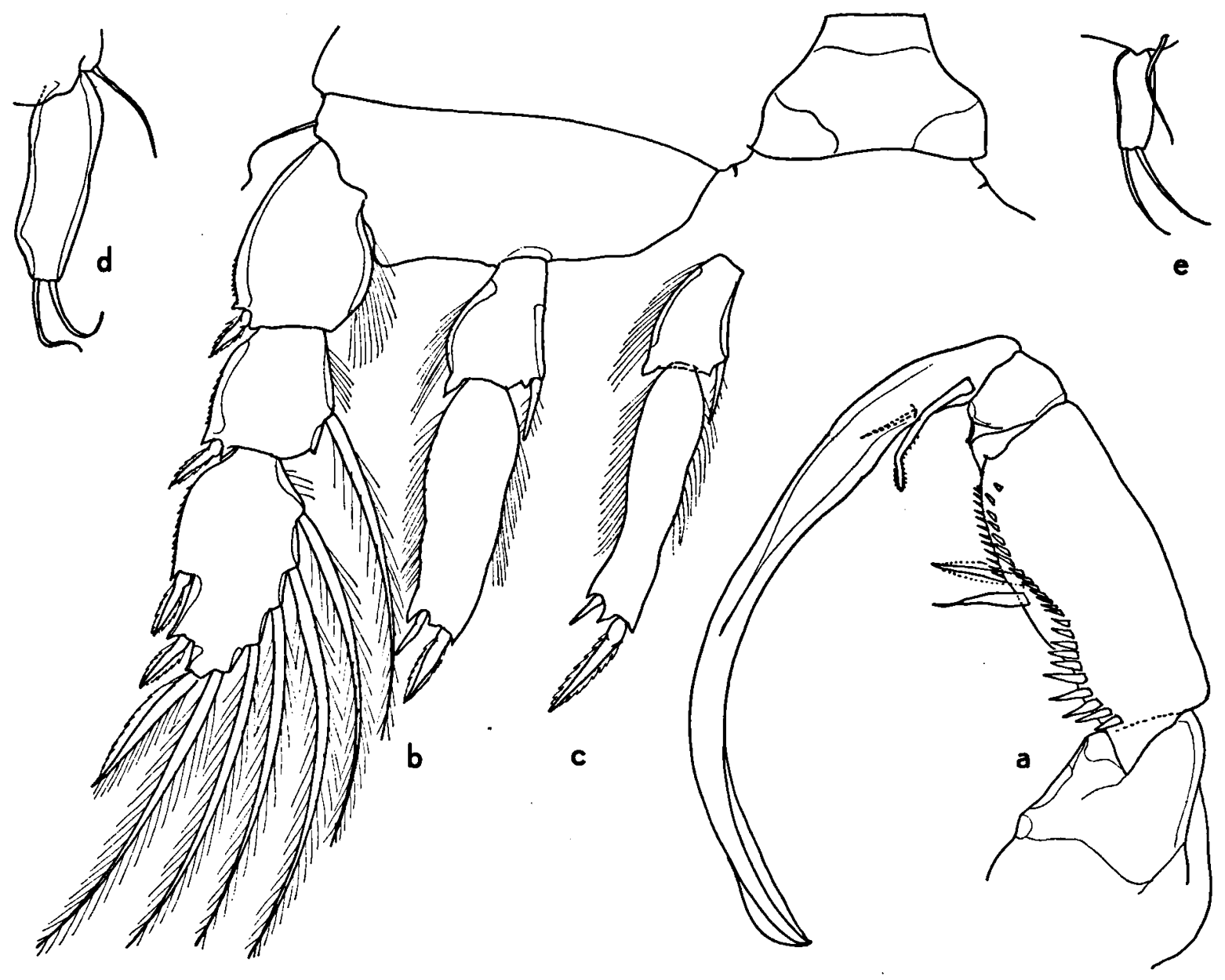

Fig. 8. Acanthomolgus mononyx n. sp. (paratypes from Curaçao). a, Mxp. ô (scale B); b, P4 ㅇ (B); c, P4 ô,

seta. P4 end. 2 bears a longer medial and a shorter lateral spine in terminal position.

P5 (fig. 8d) is $50-59 \mu \mathrm{m}$ long and has a maximal diameter of $18-20 \mu \mathrm{m}$. Its margins are unadorned, slightly sinuous but without major lobes or expansions. Terminal setae shorter than the article, naked.

Ma le: Body (fig. 6c) much more slender than in the fermale; length $851-879 \mu \mathrm{m}$ (mean, based on 4 specimens, $864 \mu \mathrm{m}$ ); greatest diameter of cephalosome 317-341 $\mu \mathrm{m}$ (mean $329 \mu \mathrm{m})$. Genital segment relatively large (222 $\mu \mathrm{m}$ long, $191 \mu \mathrm{m}$ wide). Fu. of the same shape as in female, but smaller $(56 \times 24 \mu \mathrm{m})$.

The Al is segmented and armed as in the female, but has 3 additional aesthetes, the implantation of which is indicated by black dots in fig. 6g: 2 on article 2, and 1 on article 4.

The A2 (fig. 6f) has heavy, spiniform elements end. (B); d, P5 9 (B); e, P5 of (B).

on the inner margin of articles 1 and 2. Article 2 bears a number of warts on the inner, a row of minute spinules on the outer margin. In its other features, this appendage is similar to that of the female. Article 2 is $56 \mu \mathrm{m}$ long (along the outer margin) and $33 \mu \mathrm{m}$ wide. Article 4 is $59 \mu \mathrm{m}$ long along the outer margin, $42 \mu \mathrm{m}$ along the inner margin, and $21 \mu \mathrm{m}$ wide. The terminal claw is $45 \mu \mathrm{m}$ long along its axis.

Mouth parts like those of the female.

The Mxp. (fig. 8a) consists of a "hand" made up of 3 articles, and of a long curved claw. Article 1 is unarmed; article 2 bears 2 longitudinal nows of spinules and 2 inner spines; article 3 is unarmed; the claw bears 1 curved, barbed, basal element and a subbasal seta.

P1 and P2 are like those of the female, except for the end. 3. In P1 (fig. 7d) this article bears, instead of the long, plumose, terminal seta found in the female, a short, spiniform (but plumose) 
seta. In P2 (fig. 7f), the terminal spiniform processes on this article are of unequal length in $\sigma^{\circ}$, of equal length in $o$.

The P4 end. is more slender than in $\%$, more in particular end. 2 (fig. 8c).

P5 (fig. 8e) is regularly rectangular in outline, $29 \times 11 \mu \mathrm{m}$. The distal setae are about as long as the article, naked.

Colour of live specimens. - Body white, with several brown or dirty-lillac dots, especially on the cephalosome; eye pale red.

Place in the host. -

The material was obtained through repeated washings of the octocoral in a mixture of about 5\% ethyl aloohol in seawater. The first washings (after leaving the host overnight in the mixture) did never reveal any specimens of this species. Only the later washings, 3 days after the stant of the procedure, when the host was gradually decomposing, revealed specimens of the present copepod, together with numerous, endoparasitic, Lamippidae. It is concluded, therefore, that this species of Acanthomolgus is likewise endoparasitic, and judging from its size the only likely place where it could live would appear to be the gastric cavity of the polyps.

\section{Etymology. -}

The proposed specific name, mononyx (derived from the Greek words $\mu$ ó $v o \varsigma=$ one, and ${ }^{\prime} \nu v \xi=$ claw) alludes to the terminal armature of the A2.

Comparison with other species in the genus. -

$A$. mononyx occupies a rather isolated position, chiefly by its unarmed P5 ( $\left.O \sigma^{7}\right)$, and the lack of a mediobasal lobe in P5 $\%$. Additional special features are the widened prosome $(q)$, and the robust 4th article of the $A 2\left(9 \delta^{\circ}\right)$, as well as the heavy and long A2 claw.

\section{Acanthomolgus seticomis n. sp. Figs. 9-10.}

Material examined. -

From the octocoral Plexaurella dichotoma.

St. Martin: Little Bay; 1 \& (holotype), 1 \& (allotype), $29 \&, 11 \hat{\delta}$, and 8 copepodids (paratypes); depth about $3 \mathrm{~m}$; Feb. 7, 1959 (ZMA coll. no. Co. 102,571 a-c).

\section{Description. -}

F e m a l e : Length of the body 809-942 $\mu \mathrm{m}$ (mean based on 5 specimens, $886 \mu \mathrm{m})$; greatest width of cephalosome 345-394 $\mu \mathrm{m}$ (mean $368 \mu \mathrm{m}$ ). Body (fig. 9a) rather slender in general shape. Genital somlite (fig. 9b) measured from the dorsal side, in situ in lactophenol, is $122 \mu \mathrm{m}$ wide and $100 \mu \mathrm{m}$ long. The genital area (fig. 9d) looks somewhat different from most other species in the West Indies, in that the caudal sclerite does not show a medioposterior triangular projection; the medial sclenite does present the - usual - spiniform projection, but there is no terminal setule on this projection; of the two elements on the caudal sclerite, one is heavy and spiniform, the other is more setiform, their lengths being 21 and $20 \mu \mathrm{m}$, respectively. Complete ovisacs lacking in my material; individual eggs rather small (diameter 47 $55 \mu \mathrm{m}$ ). Fu. (fig. 9e) much shorter than the anal somite, $35 \mu \mathrm{m}$ long, $27 \mu \mathrm{m}$ wide (length/width ratio 1.29 : 1). Furcal setae long, the 2 longest are plumose, the others are naked; dorsal seta longer than the ramus $(58 \mu \mathrm{m})$.

A1 resembling that of $A$. muriceanus; lengths of the articles, measured along their posterior margin, are $23,79,23,44,47,34$, and $34 \mu \mathrm{m}$, respectively; article 1 , measured along its anterior margin, is $56 \mu \mathrm{m}$ long.

A2 (fig. 9f): Article 1 with 2 conical spinules and 1 distal seta. Article 2 with 2 rows of spinules along the outer margin and 1 seta on the inner margin; measured along the outer margin, article 2 is $81 \mu \mathrm{m}$ long (thus distinctly longer than article 4). Article 3 with 3 curved setae. Article 4 without rows of spinules; $68 \mu \mathrm{m}$ long along the outer margin, $52 \mu \mathrm{m}$ along the inner margin; width $17 \mu \mathrm{m}$; the distal armature consists of 1 long and 3 short outer setae, and of 2 setae at the base of the claw. The claw is $28 \mu \mathrm{m}$ long, along its axis.

The Md. and Mxl are as in A. muriceanus (cf. Humes, 1973, figs. 10 and 11).

The $\mathrm{Mx} 2$ resembles that of $\boldsymbol{A}$. longidactylus (cf. present paper, fig. 16i).

The Mxp. (fig. 9h) has a rather inflated 2nd article, armed with 1 short and 1 long element. Distal armature consisting of a seta, a spine and a pointed endite, the latter slightly longer than the spine.

The P1 (fig. 10a) has a plumose coxp. seta; the spiniform processes on the end. articles are rather long; end. 3 bears 4 "normal", plumose setae on the median side, a lateroterminal spine, and a terminal seta, the latter plumose but slightly transformed (basal part inflated).

P2 and P3 are similar to those of muriceanus (cf. Humes, 1973, figs. 16 and 18); spiniform processes on end. 3 long (fig. 10d); lateral coxp. seta plumose.

P4 (fig. 10e) with a long, plumose, lateral coxp. seta. Exp. 3 with rather long spiniform processes; terminal exp. spine excessively long; end. 2 slender, 


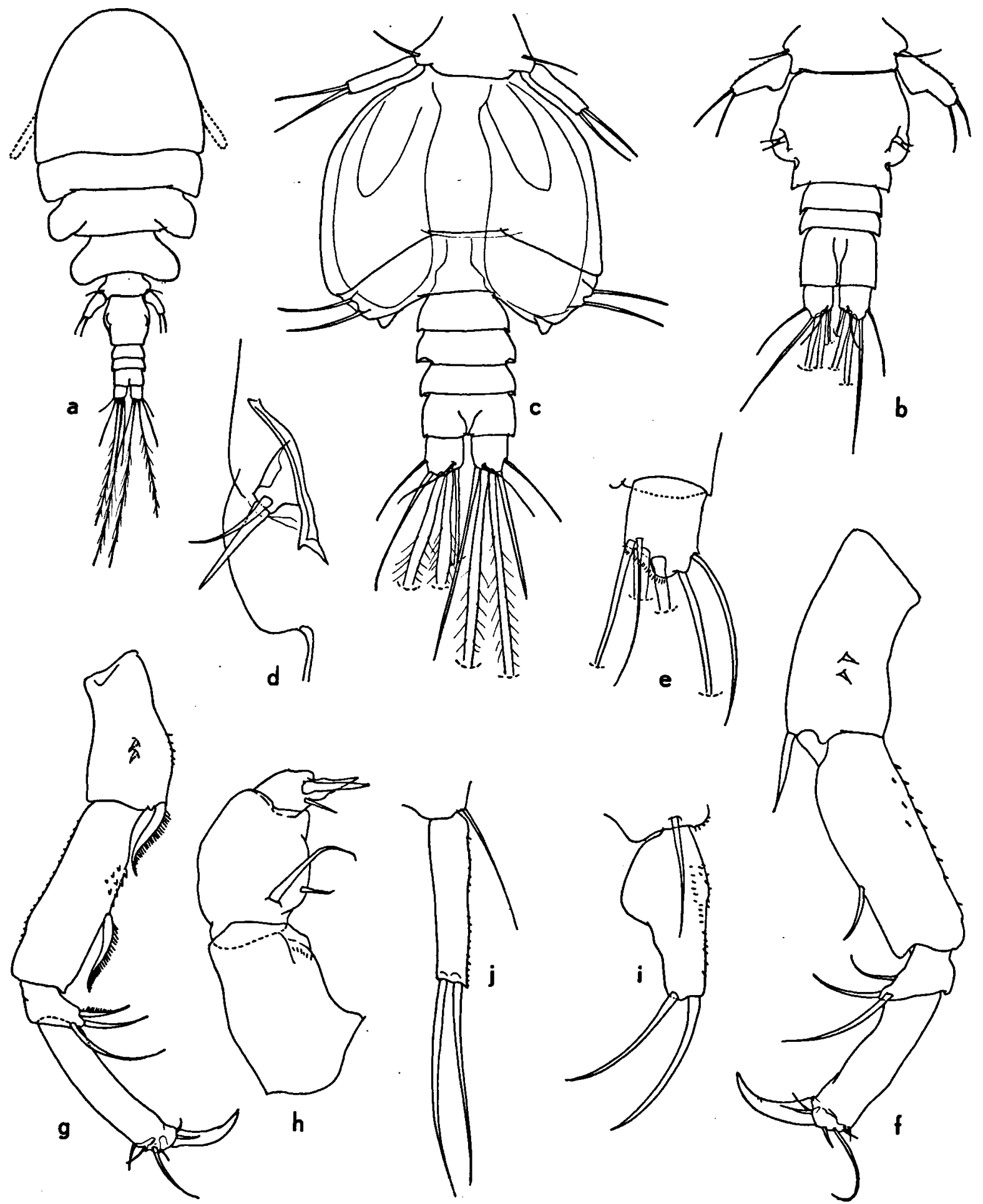

Fig. 9. Acanthomolgus seticornis n. sp. (paratypes from St. Martin). a, \&, dorsal (scale A); b, urosome, $q$, dorsal (E); c, urosome, $\hat{\jmath}$, dorsal (C); d, genital area, $\$$, dorsal

(D); e, Fu. \&, dorsal (B); f, A2 $ᄋ$ (B); g, A2 of (B); h, Mxp. $\%$ (B); i, P5 $\&$ (B); j, P5 of (D). 


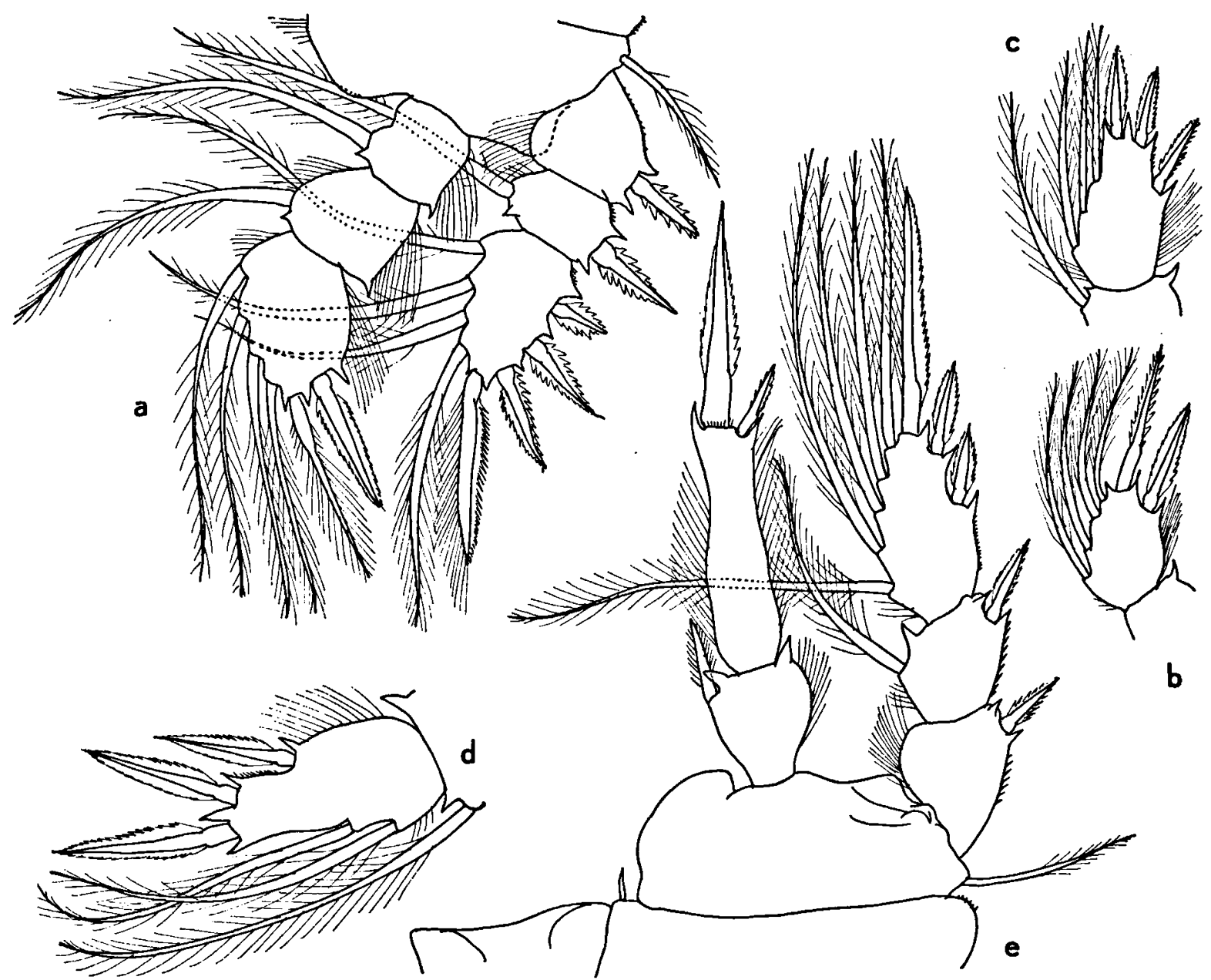

Fig. 10. Acanthomolgus seticornis n. sp. (paratypes from St. Martin). a, P1 $\$$ (scale B); b, P1 $\delta$, end. 3 (B); c,

with long spiniform processes; median element on end. 1 spiniform but with shont plumosities.

P5 (fig. 9i) with a regular swelling in its mediobasal part; length of the article $65 \mu \mathrm{m}$, greatest diameter $32 \mu \mathrm{m}$; distal diameter $11 \mu \mathrm{m}$. Distally, the P5 bears 2 subequal, naked setae of $48-50 \mu \mathrm{m}$ long. The lateral margin of the article bears 2 rows of very small spinules.

Ma le : Length 655-711 $\mu \mathrm{m}$ (mean, based on 5 specimens, $682 \mu \mathrm{m})$; greatest width of cephalosome 245-273 $\mu \mathrm{m}$ (mean $258 \mu \mathrm{m}$ ). Genital somite (fig. 9c) $141 \mu \mathrm{m}$ long, $157 \mu \mathrm{m}$ wide. Fu. (fig. 9c) $19 \mu \mathrm{m}$ long, $20 \mu \mathrm{m}$ wide.

Al as in female, but with the usual 3 extra aesthetes added.

A2 (fig. 9g) with transformed elements (spiniform, sigmoid, pectinated) on articles 1 and 2. Article 2 is $66 \mu \mathrm{m}$ long (along its outer margin); outer margin with a row of minute spinules; inner
P2 8 , end. 3 (B); d, P3 $\%$, end. 3 (B); e, P4 $\$$ (B).

margin with small, scattered, spiniform processes ("warts"). Article 3: shortest element finely pectinated, other two elements naked. Article 4: 64 $\mu \mathrm{m}$ long along the outer margin, $51 \mu \mathrm{m}$ along the inner margin; width $13 \mu \mathrm{m}$; distal armature as in o. Length of terminal claw $25 \mu \mathrm{m}$.

Mouth parts as in female.

Mxp. as in $A$. aequiseta (cf. fig. $11 \mathrm{~g}$ in the present paper).

P1 (fig. 10b): the spiniform processes on end. 3 are about as long as in $\%$; the transformed terminal seta of the female is replaced by a coarsely barbed spine; the lateroterminal spine is not transformed.

P2 has 3 spines and 3 setae on the 3rd end. article (fig. 10c); the central one of the 3 spines is hardly less well-developed than the other 2 .

P3 and P4 practically as in 9 .

P5 (fig. 9j) is slender, 36-37 $\mu \mathrm{m}$ long, 8-9 $\mu \mathrm{m}$ wide; it bears 2 long, naked, subequal terminal 
setae; lateral margin with a row of minute spinules.

$$
\text { Colour. - Unknown. }
$$

Remarks. -

In the long 2nd article of A2 $\left(9 \sigma^{\circ}\right)$ and in the equal length of the setae on P5 $(\%)$, the present spocies resembles $A$. aequiseta n. sp. (vide infra). It differs, however, in many details, the most obvious of which are the minute (versus conspicuous) spinules on the outer margin of P5 $\left(q \delta^{*}\right)$, the shorter $\mathrm{Fu} .(\%)$, and in particular the presence of 1 long seta on the distal end of article 4 of A2 $\left(9 \sigma^{*}\right)$. This latter character, which has inspired the proposed specific name, seticornis, distinguishes the present species from all West Indian representatives of Acanthomolgus (mononyx-group), though it is found in some species of the dionyxgroup (dionyx, bilobipes).

\section{Acanthomolgus aequiseta n. sp. Fig. 11.}

Material examined. -

From the gorgonian Muricea laxa.

Curaçao: about $500 \mathrm{~m}$ W. of Piscadera; $3 q, 5$ \&, 5 \% (juv.); reef slope, depth 34-41 m; March 26 and 29, 1974 $(1 \propto$ is made the holotype, $1 \delta$ the allotype, the remaining specimens are paratypes; ZMA coll. no. Co. 102,575 a-c).

\section{Description. -}

F e m a l e (fig. 11a): Length of 2 specimens 1006 and $1078 \mu \mathrm{m}$. Prosome rather wide (443 and 513 $\mu \mathrm{m})$. Fu. (fig. 11a, c) distinctly shorter than the anal somite, 46-48 $\mu \mathrm{m}$ long, and 30-33 $\mu \mathrm{m}$ wide (length/width ratio 1.45-1.53). In all females available, the furcal setae are partially broken; dorsal seta much longer than the width of the ramus, plumose.

A1 resembling that of $A$. mononyx (cf. present paper, fig. $6 \mathrm{~g}$ ); the lengths of the articles, measured along the posterior margin, are 28, 101, 30, 58, 55,43 , and $40 \mu \mathrm{m}$, respectively.

The A2 (fig. 11d) has 2 to 4 spinules on its basal article. Article 2 bears an outer row of spinules and is $77 \mu \mathrm{m}$ long (along the outer margin). Article 4 is slender, devoid of rows of spinules, 59 $\mu \mathrm{m}$ long along the inner margin, $76 \mu \mathrm{m}$ along the outer margin, and $13 \mu \mathrm{m}$ wide. Claw relatively shont, $30 \mu \mathrm{m}$ along its axis. None of the setules on anticle 4 is very long.

The Md., Mx1, and Mx2 are as in A. muriceanus (cf. Humes, 1973, figs. 10, 11, and 12, respectively).

The Mxp. (fig. 111) has several groups of spinules on article 1 . Article 3 has a pointed endite which is subequal to the large spine; I have been unable to find a setiform element on article 3, though it is present in other species.

The P1 resembles that of $A$. bayeri (cf. Humes, 1973, fig. 69), in particular in that the terminal spine of exp. 3 is almost as long as the subterminal seta (fig. 11h). End. 3 (fig. 11i) has 1 finely serrated spine and 5 setae. The lateral coxp. seta is plumose.

The $\mathrm{P} 2$ resembles that of $A$. muriceanus (cf. Humes, 1973, fig. 16), except for the lateral coxp. seta that is plumose in the present species.

P3 resembles likewise that of $A$. muriceanus (cf. Humes, 1973, fig. 18), but the lateral coxp. seta is longer than exp. 1 and it is plumose.

The P4 resembles that of $A$. bayeri (of. Humes, 1973. fig. 71), although the lateral coxp. seta is slightly longer in the present form, and is moreover plumose.

The P5 (fig. 11) is $84 \mu \mathrm{m}$ long (along its lateral margin); its greatest diameter (at the level of the regularly shaped mediobasal swelling) is $36 \mu \mathrm{m}$. The lateral margin beans 1 row of smaller and 1 row of larger spinules; the longest of these reach a length of $7 \mu \mathrm{m}$; none of these spinules is implanted near the insertion of the medial, terminal seta. The 2 terminal setae are, unlike in most species (except for $\boldsymbol{A}$. mononyx and $\boldsymbol{A}$. seticornis) of about equal length.

The genital area (fig. 11n) has a triangular projection on the caudal sclerite; the 2 elements on the same sclerite are rather short and heavy, spiniform.

M a le : Length of the body $640 \mu \mathrm{m}$, greatest width $256 \mu \mathrm{m}$. Genital somite (fig. 11b) with a narrowly pointed projection and 2 setae on either side; length (in the midline) $105 \mu \mathrm{m}$, greatest width $128 \mu \mathrm{m}$. Fu. (fig. 11b) 24-26 $\mu \mathrm{m}$ long, 21$22 \mu \mathrm{m}$ wide.

The A2 (fig. 11e) bearing some spinules and a transformed, pectinated, spine on article 1. Article 2 is $69 \mu \mathrm{m}$ long (along its outer margin); inner margin with some conical spiniform projections and 1 subterminal spine. Claw-like setae on article 3 naked. Article 4 slender, $62 \mu \mathrm{m}$ long along the inner margin, $73 \mu \mathrm{m}$ allong the outer margin, and $10 \mu \mathrm{m}$ wide. Claw $35 \mu \mathrm{m}$ long, slender.

Mxp. (fig. 11g) fundamentally built as in the other species; article 2, however, rather slender.

P1 end. sexually dimorphous (fig. 11j): articles 1,2 , and 3 are more elongated in shape than in the female. End. 3 with a non-transformed inner spine, a transformed terminal spine, and 4 setae. 

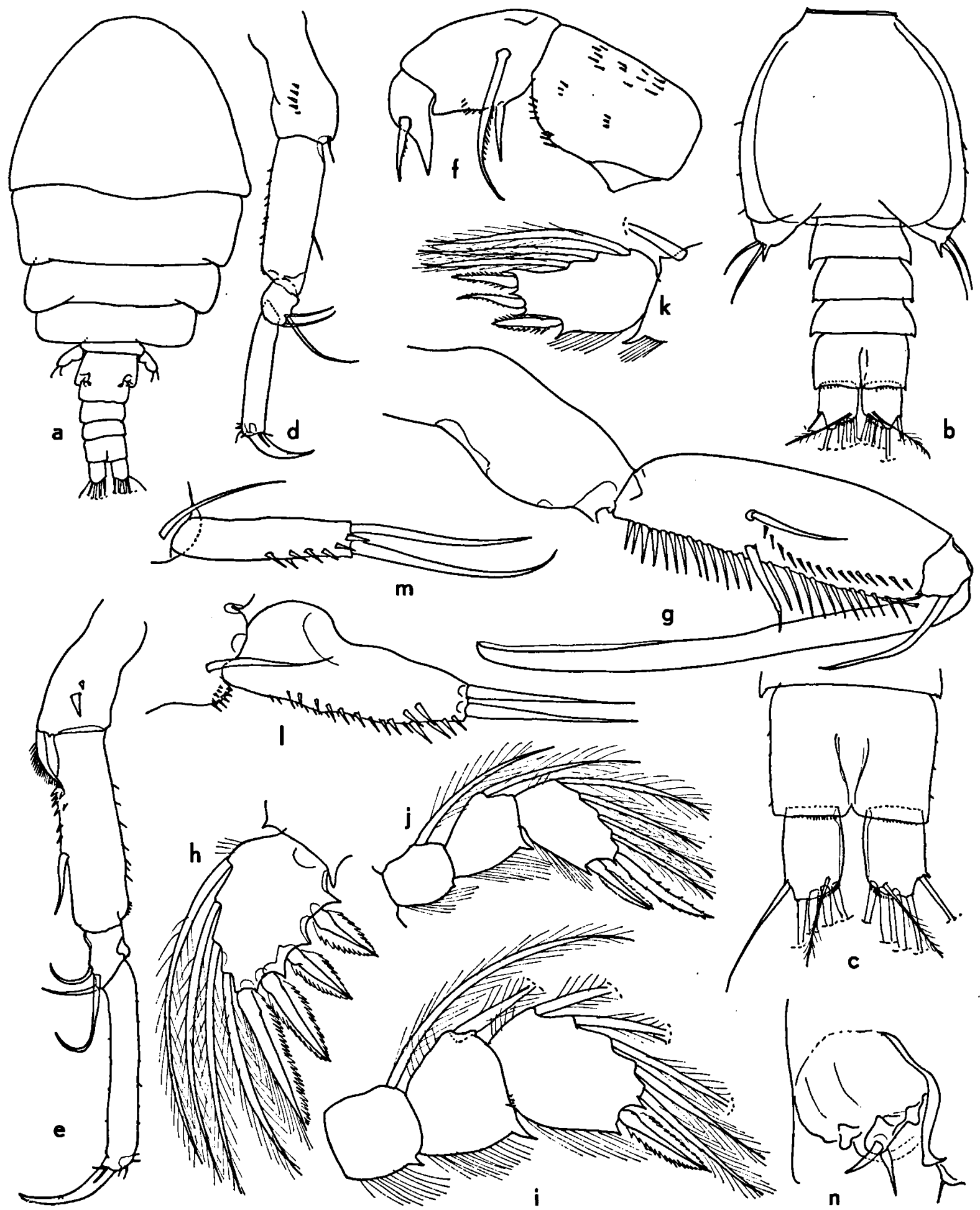

Fig. 11. Acanthomolgus aequiseta n. sp. (paratypes from Curaçao). a, $\$$, dorsal (scale A); b, urosome, $\hat{o}$, dorsal (C); c, anal somite and Fu. \&, dorsal (C); d, A2 \& (C);

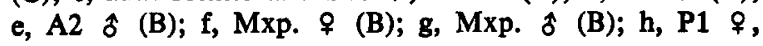

exp. 3 (B); i, P1 $\&$, end. (B); j, P1 $\hat{\delta}$, end. (B); $k, P 2 \hat{o}$, end. 3 (B); 1, P5 $\&$ (B); m, P5 of (D); n, genital area, $\%$ (D). 
The transformed terminal spine bears some 6 widely spaced marginal denticles on either edge.

$\mathrm{P} 2$ end. 3 (fig. 11k) bears 3 tall spiniform processes; the medioterminal spine is more feebly developed than the 2 other spines.

The P5 (fig. $11 \mathrm{~m}$ ) is $40 \times 10 \mu \mathrm{m}$. Lateral margin with stout spinules. Two subequal terminal setae.

Colour of live specimens. - Body whitish or slightly yellowish; eye large, red.

\section{Remarks. -}

By the A2 (which has a terminal claw that is short in proportion to the length of article 4) and by the P5 $\left(i \sigma^{*}\right)$ (which bears conspicuous lateral spinules), the present species is connected with $A$. muriceanus and $A$. affinis. These two differ in having a relatively shonter 2 nd article in the A2 $\left(q \sigma^{*}\right)$, a longer Fu. $\left(q \sigma^{*}\right)$, and very unequal setae on P5 (q).

In the slenderness of the 2 nd anticle of $\mathrm{A} 2$, the present species resembles $A$. intermedius. The latter has, however, likewise very unequal setae on P5 ( $q$ ), and a different armature (with minute spinules only) of the lateral margin of P5 $\left(q 0^{*}\right)$, greater inequality of the elements on the 2nd Mxp. article ( $q)$, no sexual differences in the spiniform processes of the $\mathrm{P} 2$ end., etc.

Etymology. -

The proposed specific name, aequiseta, alludes to the two setae of about equall length on the P5 $q$.

\section{Acanthomolgus intermedius n. sp. Fig. 12.}

Material examined. -

From the octocoral Eunicea laciniata.

Curaçao: about $500 \mathrm{~m} \mathrm{~W}$. of Piscadera; 1 \& (holotype), $1 \delta$ (allotype), $3 \&, 8 \delta$, and 3 juvs. (paratypes); reef flat; depth about $6 \mathrm{~m}$; March 27, 1974 (ZMA coll. no. Co. 102,561 a-c).

Description. -

Very similar in most details to the complex of species centered around $A$. muriceanus.

The body of the female (fig. 12a) is 990-1006 $\mu \mathrm{m}$ long, of the male 830-840 $\mu \mathrm{m}$.

The A1 $\left(q \sigma^{\circ}\right), \mathrm{Md} .\left(\% \sigma^{*}\right)$, and $\operatorname{Mx1}\left(q \sigma^{*}\right)$ are similar to those found in $A$. muriceanus. The Mx2 $\left(q \sigma^{*}\right)$ and P4 $\left(q \sigma^{x}\right)$ resemble those of $A$. longidactylus.

The genital area ( $q$ ) (fig. 12l) has a small, slightly rounded triangular projection on the caudal sclerite.

The lengths of the articles of the A1 ( $q)$, mea- sured along the posterior margin, are: $34,93,21$, $42,49,34$, and $32 \mu \mathrm{m}$, respectively. Article 1 measures $54 \mu \mathrm{m}$ along the anterior margin. For the A1 $\left(\delta^{*}\right)$ these lengths are $37,70,19,32,38,30$, and $29 \mu \mathrm{m}$ (along the posterior margin) and $48 \mu \mathrm{m}$ (for article 1 along the anterior margin).

The A2 (q) (fig. 12d) is reminiscent of A. muriceanus, in that the claw is relatively short. Article 1 bears 5 spinules and an inner distal setule. Article 2 is more than twice as long as wide (71$75 \mu \mathrm{m}$ long along its outer margin, $33 \mu \mathrm{m}$ wide) and bears an outer row of marginal spinules and an inner setule. Article 4 is devoid of rows of spinules; it is $78 \mu \mathrm{m}$ long along its outer margin, 63 $\mu \mathrm{m}$ along its inner margin, and $17 \mu \mathrm{m}$ wide. The terminal claw is $32 \mu \mathrm{m}$ long along its axis. For the A2 $\left(\sigma^{*}\right)$ these measurements are 69-71 $\mu \mathrm{m}$ and $30 \mu \mathrm{m}$ for article $2,73 \mu \mathrm{m}, 60 \mu \mathrm{m}$, and $13 \mu \mathrm{m}$ for article 4 , and $33 \mu \mathrm{m}$ for the claw, respectively.

The A2 ( $\left.\sigma^{*}\right)$ (fig. 12e) has 2 modified elements, 1 on article 1 and 1 on article 2; these elements are provided with minute barbelations, they are sigmoid, spiniform, and longer than the corresponding elements in $q$; article 2 bears some 4 triangular "warts" on the inner side, and a row of minute spinules on the outer margin. The shortest of the 3 elements on article 3 is provided with a comb-like row of fine denticles (the corresponding element in $q$ is naked). Anticle 4 bears a row of minute spinules on either margin; it is more slender than in $q$.

The Mxp. ( $q$ ) (fig. 12f) has a swollen 2nd article, which bears 2 very unequal elements; the distal structure (long spine, shorter endite) is reminiscent of $\boldsymbol{A}$. longidactylus.

The P1 ( $q$ ) (fig. $12 \mathrm{~g}$ ) is similar to that in $A$. affinis. In $\sigma^{\circ}$, end. 3 (fig. 12h) bears 2 spines, the terminalmost of which is coarsely serrated, but less pronounced so than in $A$. aequiseta. End. 2 $\left(\sigma^{*}\right)$ is more ellongate and more rectangular in shape than in 9 .

End. 3 of $\mathrm{P2}\left(\sigma^{7}\right)$ (fiig. $12 \mathrm{~m}$ ) has short spiniform processes. The centralmost spine on end. 3 is feeble.

The P5 ( $q$ ) is $80 \mu \mathrm{m}$ long, at a maximum width of $34 \mu \mathrm{m}$; the mediobasal swelling is of variable shape (of. figs. 12i and 12j). The lateral margin bears a row of minute (length $3 \mu \mathrm{m}$ ) spinules. The 2 terminal elements are of very different length (36 and $62 \mu \mathrm{m})$.

The P5 ( $\left.\sigma^{7}\right)$ (fig. $12 \mathrm{k}$ ) is $36 \times 7.5 \mu \mathrm{m}$; the lateral margin bears some minute spinules.

The Fu. ( $)$ ) (fig. 12b) is $51 \times 27 \mu \mathrm{m}$; the distal margin is provided with a distinct hyaline fringe. 

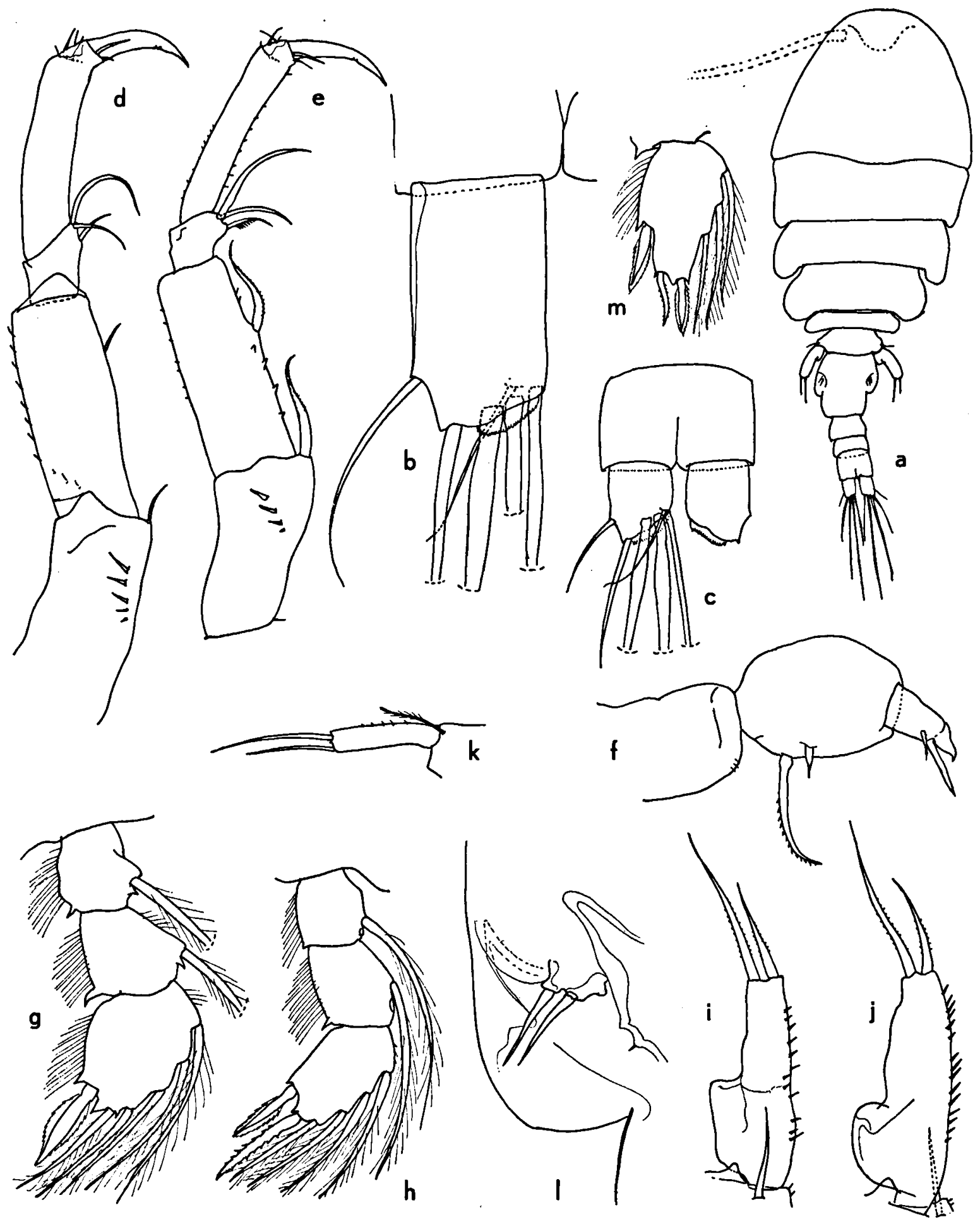

Fig. 12. Acanthomolgus intermedius n. sp. (paratypes from Curaçao). a, $\%$, dorsal (scale A); b, Fu. \&, ventral e, A2 of (B); f, Mxp. $\&$ (B); g, P1 $\&$, end. (B); h, P1 $\hat{o}$, end. (B); $i, j, P 5 \%$, of different specimens (B); $k$, (D); c, anal somite and Fu. $\widehat{\delta}$, dorsal (B); d, A2 9 (B); P5 $\hat{f}$ (B); 1 , genital area, + (D); $\mathrm{m}, \mathrm{P2} \hat{\jmath}$, end. 3 (B). 
The thin dorsal seta is fairly long $(35 \mu \mathrm{m})$. The Fu. $\left(\sigma^{7}\right)$ is $28 \times 22 \mu \mathrm{m}$ (fig. 12c).

Colour. - Unknown.

Remarks. -

In the length of the $\mathrm{A} 2$ claw $\left(9 \sigma^{*}\right)$ the present species resembles such species as $A$. affinis, $A$. longidactylus, $A$. longifurca, and to a lesser degree $A$. muriceanus. The lateral margin of P5 ( $\left.9 \delta^{7}\right)$ bears only small spinules in the new species, thus agreeing with $A$. seticornis, longidactylus, bayeri, verrucipes, and longifurca. The slender 2 nd article of $\mathrm{A} 2\left(\% \sigma^{*}\right)$ of the present species is shared by $A$. aequiseta and $A$. seticornis. The proposed specific name, intermedius, alludes to the somewhat mixed nature of the characters of this species.

In addition to the differences between these various species as enumerated in table $I$, the following features of $\boldsymbol{A}$. intermedius may prove useful in discriminating it from related species: the great difference in mutual length of the endite and terminal spine of the Mxp. $\%$; the presence of an inner spine on article 2 of A2 $\sigma^{\circ}$ (is a seta in $\boldsymbol{A}$. muriceanus); the pectinated nature of one element on article 3 of A2 $\sigma^{*}$ (naked in muriceanus, longifurca, bayeri, verrucipes, and aequiseta); the relatively long dorsal seta of the Fu. $\$$ (shorter than the diameter of the ramus in muriceanus); the presence of a row of spinules on the outer margin of anticle 2 of A2 or (absent in verrucipes); the long medial element at the base of the main lash of $\mathrm{Mx} 2\left(\sigma^{\circ}\right)$ ('short in bayeri).

Acanthomolgus affinis n. sp. Fig. 13.

Syn.: Acanthomolgus muriceanus "variant population on Plexaura". — Humes, 1973: 92-94, figs. 31-33.

Material examined. -

On Plexaura homomalla:

Curaçao: Jan Thiel Bay, outside the pier of the swimming pool; 1 \& (holotype), 1 के (allotype), 19 \&, 15 oे (paratypes); depth about $3 \mathrm{~m}$; Feb. 28, 1974 (ZMA coll. no. Co. 102,572 a-c).

Curaçao: Santa Martha Bay; 8 $\%, 2 \delta$; depth about $3 \mathrm{~m}$; Oct. 8, 1958.

On Plexaura flexuosa:

Curaçao: Santa Martha Bay; 6 \&, 1 s; depth about 3 m; Oct. 8-12, 1958.

Curaçao: Piscadera Bay; 1 s ; depth about $2 \mathrm{~m}$; Nov. 11, 1958.

Description. -

These copepods are very similar to $A$. muriceanus (vide infra), but differ in a few details. Humes (1973) on the ground of material from Bermuda only, did not consider these details sufficient to warrant the creation of a new species. Since the differences with $\boldsymbol{A}$. muriceanus prove to be constant in Bermudan material and in the present material from Curaçao, since a couple of additional differences have been disoovered, and since the existing differences are of the same magnitude as those between certain other species of Acanthomolgus, I do consider the "Plexaura variant population" a full species.

The body of the female is 1006-1115 $\mu \mathrm{m}$ long (mean, based on 4 specimens, $1069 \mu \mathrm{m}$ ); greatest width of cephalosome 460-504 $\mu \mathrm{m}$ (mean $478 \mu \mathrm{m}$ ). The body of the male is 735-891 $\mu \mathrm{m}$ long (mean, based on 4 specimens, $822 \mu \mathrm{m}$ ), greatest width of cephalosome 282-334 $\mu \mathrm{m}$ (mean $318 \mu \mathrm{m}$ ).

The genital area $(q)$ is as described and illustrated by Humes, 1973 (fig. 31).

The A1 $q$ resembles that of $A$. muriceanus; the lengths of the anticles, measured along the posterior margin, are $38,91,27,42,52,37$, and $33 \mu \mathrm{m}$; article 1 is $66 \mu \mathrm{m}$ long along the anterior margin. For the male these lengths are $37,75,23$, $36,45,38$, and $34 \mu \mathrm{m}$ (along the posterior margin) and $53 \mu \mathrm{m}$ (along the anterior margin of article 1).

The A2 $q$ (fiig. 13a) bears 3 spinules on article 1 ; article 2 is much less than twice as long as wide $(49 \times 34 \mu \mathrm{m})$ and bears a row of outer spimules; article 4 lacks such a row of spinules. Article 4 is $98 \mu \mathrm{m}$ long along its outer margin, 71 $\mu \mathrm{m}$ along its inner margin, and $25 \mu \mathrm{m}$ wide. The terminal claw is $59 \mu \mathrm{m}$ long along its axis.

The A2 $\sigma^{\circ}$ (fig. 13b) bears 1 spinule on article 1; the inner distal element is transformed into a dagger-like spine, armed along its inner margin with a row of cilia. Article 2 is less than twice as long as wide $(71 \times 40 \mu \mathrm{m})$ and bears an outer row of spinules, the inner surface bears a number of conical cuticular projections ("warts"), and a transformed, unilaterally ciliated, element. Article 3 bears 3 claw-like setae, the most proximal of which is "pectinated" in aspect (through the presence of a now of fine denticles on one margin). Article 4 bears a row of spinules on the inner margin; the article is $103 \mu \mathrm{m}$ long along its outer margin, $90 \mu \mathrm{m}$ along its inner margin, and $15 \mu \mathrm{m}$ wide. The terminal olaw is $58 \mu \mathrm{m}$ long along its axis.

Mxp. ( $q$ ) as illustrated (fig. 13c).

The P1 $q$ (fig. 13d) is as described below for A. muriceanus. The P1 $\sigma^{*}$ is sexually dimorphous, both in shape and in armature, of the endopodite (fig. 13e): end. 1 and end. 2 are more elongated 
than in $q$; the medial seta on end. 2 is implanted at some distance from the distal articulation of the article, whereas in $q$ it is implanted near that articulation. The 2 distal elements are spiniform, the medial one is coarsely barbed, the lateral one is finely barbed on the inner margin, almost smooth at the outer margin.

P2, P3, and P4 of the $q$ resemble those of $A$. muriceanus (figures in Humes, 1973). P2 $\sigma^{*}$ (fig. 13f) has the end. 3 of a rather elongated shape; there are 3 spines, the centralmost of which is very thin in comparison with the other two.

P5 $\%$ (fig. $13 \mathrm{~g}$ ) is $115 \mu \mathrm{m}$ long and $43 \mu \mathrm{m}$ wide in its widest part. Its lateral margin bears irregularly placed, relatively large (length $10 \mu \mathrm{m}$ ) spinules.
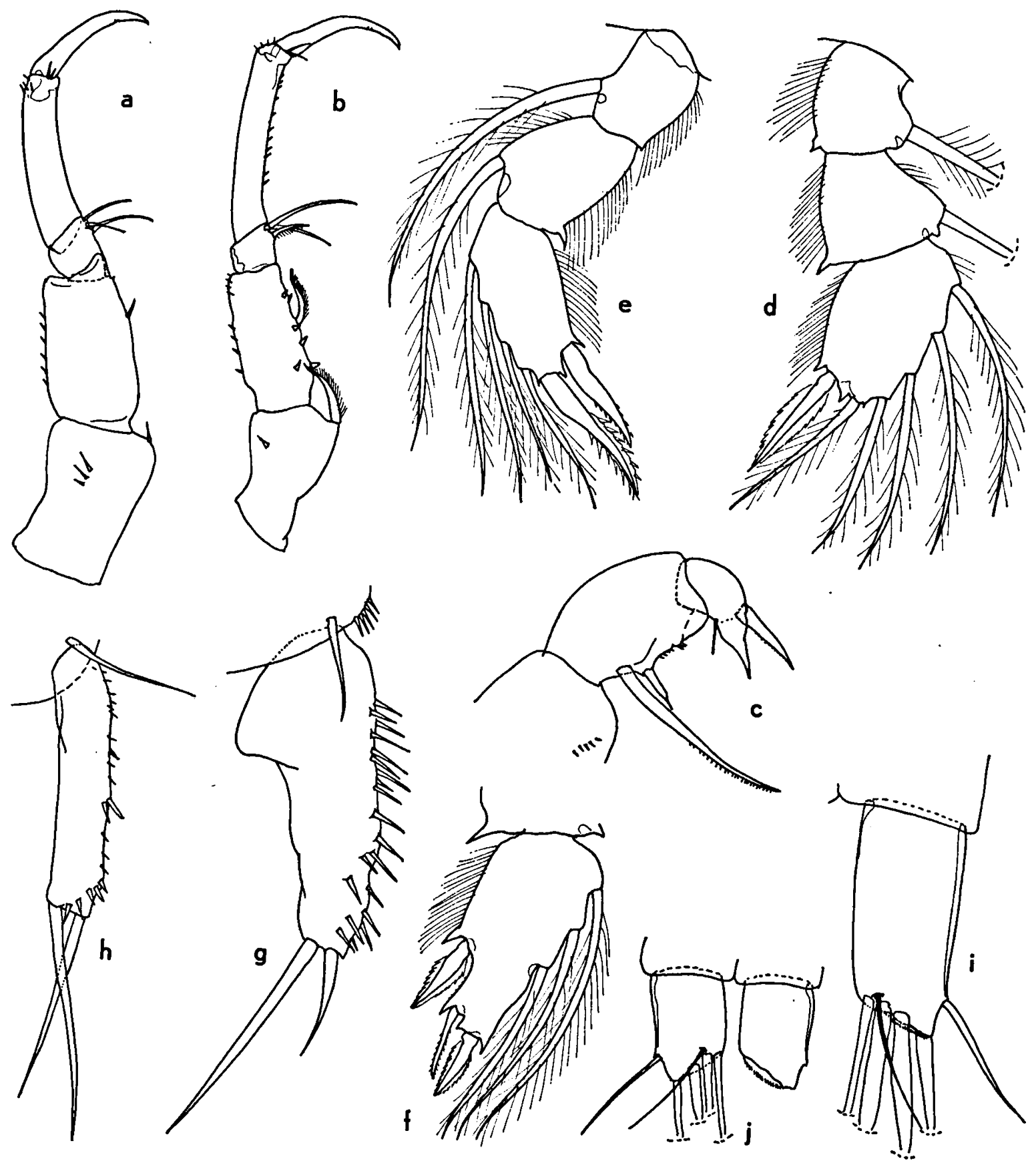

Fig. 13. Acanthomolgus affinis n. sp. (paratypes from $\mathrm{Cu}-$

d, P1 $\&$, end. (B); e, P1 $\hat{\delta}$, end. (B); f, P2 $\hat{\delta}$, end. 3 (B); raçao). a, A2 $\%$ (scale C); b, A2 ô (C); c, Mxp. + (B);

g, P5 o (B); h, P5 ô (D); i, Fu. \& (B); j, Fu. o (B). 
The P5 $\sigma^{\prime \prime}$ (fig. 13h) is $51 \times 11 \mu \mathrm{m}$, laterally armed with many smaller and several larger spinulles, the latter leave the lateral margin near the end of the article and run obliquely over the dorsal surface of the P5.

The Fu. of the $q$ is $75 \times 36 \mu \mathrm{m}$ (fig. 13i), of the $\sigma^{7} 34 \times 23 \mu \mathrm{m}$ (fig. 13j), thus with a length/ width ratio of $2.10: 1$ and of $1.48: 1$, respectively.

Other details as in A. muriceanus.

Colour of live specimens. - Body semitransparent, colourless; ovaries orange; eye bright red.

Remarks. -

$A$. affinis agrees with $A$. muriceanus mainly in the claw of the A2 ( $\left.9 \delta^{*}\right)$ whlich is distinctly shorter than anticle 4. In $A$. muriceanus it is relatively shorter, though, than in $A$. affinis (see paragraph 2 of table I for the exact ratios). Another point of agreement between $\boldsymbol{A}$. muriceanus and $\boldsymbol{A}$. affinis is the armature of the outer margin of P5 $\left(q \delta^{7}\right)$, consisting of prominent spinules.

$\boldsymbol{A}$. affinis differs from $A$. muriceanus chiefly in the following details: (1) article 2 of A2 $\sigma^{7}$ with transformed (dagger-like) spine in affinis (versus a setiform element in muriceanus); (2) article 4 of A2 $\sigma^{*}$ with a row of inner spinules in affinis (absent in muriceanus); (3) article 3 of A2 $0^{*}$ with 1 pectinated element in affinis (all elements naked in muriceanus); (4) a longer claw on A2 $\left(9 \sigma^{7}\right)$ in affinis; (5) the more pronounced sexual dimorphism in the shape of the artioles of P1 end. in affinis. Aldditionall differences, of a more relative nature, are found in the spine on article 1 of A2 $\delta$ (crenulated in muriceanus, ciliated in affinis), in the somewhat smaller mediobasal lobe of P5 $q$ in affinis, in the distinotly smaller length/width ratio of the Fu. $\sigma^{*}$ in affinis, in the greater relative slenderness of P5 $\sigma^{*}$ in affinis, etc.

Acanthomolgus muriceanus Humes, 1973. Fig. 14.

A. muriceanus Humes, 1973: 85-92, figs. 1-30 (typical form only).

Material examined. -

From the gorgonian Muricea atlantica.

Bermuda: North Reef; $5 \%, 5 \&$ (paratypes); depth $3 \mathrm{~m}$; July 26, 1962 (ZMA coll. no. Co. 102,546).

Remarks. -

This species is minutely described by Humes. In the light of the vanious now forms of Acanthomolgus found in the Netherlands' Antilles, a number of paratypes have been re-examined and the mor- phology of the exoskeleton structures has been compared with that of the other forms.

It suffices to mention a few minor details in which the present material deviates from the original description or by way of supplement to that description.

The genital area (o) (fig. 14h) does not show in the present specimens a pointed lamelliform process on the medialmost sclerite, as mentioned in the original description (this sclerite is shaped in a normal way, i.e. with a rounded proximolateral lobe and an almost as large distolateral lobe, the latter armed with a minute spinule). Instead, a small triangular process is found, also in its usual place, where it is observed also in the "variant population on Plexaura" (Humes, 1973, fig. 31 ; called $A$. affinis in the present paper), in $A$. verrucipes (cf. Humes, 1973, fig. 36), in $A$. bayeri (cf. Humes, 1973, fig. 59), and in a number of species described in the present paper. This "usual" place is near the median end of the sclerite delimiting caudally the genital area.

The A2 $q$ bears 4 or 5 spinules on article 1 (fig. 14a). Anticle 2 is $71 \mu \mathrm{m}$ long along the outer margin and $38 \mu \mathrm{m}$ wide; it bears a row of small spinules on its outer margin. Article 4 is devoid of rows of spinules; it is $94 \mu \mathrm{m}$ long along its outer edge, $71 \mu \mathrm{m}$ along its inner edge, and $19 \mu \mathrm{m}$ wide. The terminal claw has a length of $46 \mu \mathrm{m}$ along its axis.

The A2 $\sigma$ (fig. 14b) has 2 or 3 spinules on article 1; the distal element on this article is transformed (larger than in $\%$, dagger-like instead of setiform, and crenulated along the inner margin). Article 2 is $75 \mu \mathrm{m}$ long along the outer margin, and $35 \mu \mathrm{m}$ wide; the outer margin of this article bears a row of minute spinules; the inner margin is provided proximally with a few triangular projections ("warts") and subdistally with a setiform element which is longer than the homologon in 9 , but which is not transformed in a dagger-like way. The 3 olaw-like setae on article 3 are naked. Article 4 is $94 \mu \mathrm{m}$ long allong the outer margin, 74 $\mu \mathrm{m}$ along the inner margin, and $16 \mu \mathrm{m}$ wide. The terminal claw is $44 \mu \mathrm{m}$ long along its axis.

The P1 end. ( 9 ) (fig. 14c) has a triangular process over the base of a long seta on article 2, and 2 such processes on article 3 , one on either side of the spine. The endopodite articles of P1 $\sigma^{7}$ have practically the same shape as those in $O$ (fig. 14d) (thus contrary to the situation found in A. affinis, where a pronounced sexual dimorphism exists), but the armature of end. 3 is different: the 
terminal seta is replaced by a coarsely barbed spine. The medial spine is finely barbed, like the homologous spine in $q$.

The P2 end. ( $\left.\sigma^{\pi}\right)$ (fig. 14e) has 3 terminal spines, the centralmost of which is slightly more feebly developed than the others. Distally, end. 3 bears low spiniform processes. End. 2 bears a distinct spiniform process both on the laterodistal and mediodistal corners.

The P5 $q$ has an inner swelling of variable size and shape, oocupying distinctly less than half the inner margin of the article (fig. 14f). The lateral margin of P5 bears relatively stout spinules of 9 $\mu \mathrm{m}$ long. The article is $86 \mu \mathrm{m}$ long (along its axis) and its greatest diameter, at the level of the swelling, is $35 \mu \mathrm{m}$.

The P5 $\sigma^{\prime}$ (fig. $14 \mathrm{~g}$ ) is $51 \mu \mathrm{m}$ long and $14 \mu \mathrm{m}$ wide. Allong the outer margin of the article runs a row of spinules, smaller in the proximal part, longer in the distal part; near the distal end, this row leaves the lateral margin and runs over the dorsal surface of the article to the base of the innermost distal setta.

The Fu. of the $q$ is $69 \mu \mathrm{m}$ long, $31 \mu \mathrm{m}$ wide (ratio $2.21: 1$ ), of the $\sigma^{\prime \prime} 48 \mu \mathrm{m}$ long and $27 \mu \mathrm{m}$ wide (ratio $1.79: 1$ ). Distally, near the implantation of the longer terminal setae, runs an almost invisible hyaline membrane with a spinulose edge.

These additional notes have been made after paratypic specimens kindly donated by Dr. Arthur G. Humes to the Zoölogisch Museum Amsterdam. No new material of this species has been collected in the Netherlands' Antilles.

\section{Acanthomolgus longifurca n. sp. Fig. 15.}

Material examined. -

From the octocoral Eunicea tourneforti.

Curaçao: Santa Martha Bay; $100+$ specimens, females, males, and copepodids, including $1 \%$ (holotype) and $1 \hat{\delta}$ (allotype), the remaining specimens are paratypes; depth about $3 \mathrm{~m}$; Oct. 12, 1958 (ZMA coll. no. Co. 102,560 a-c).
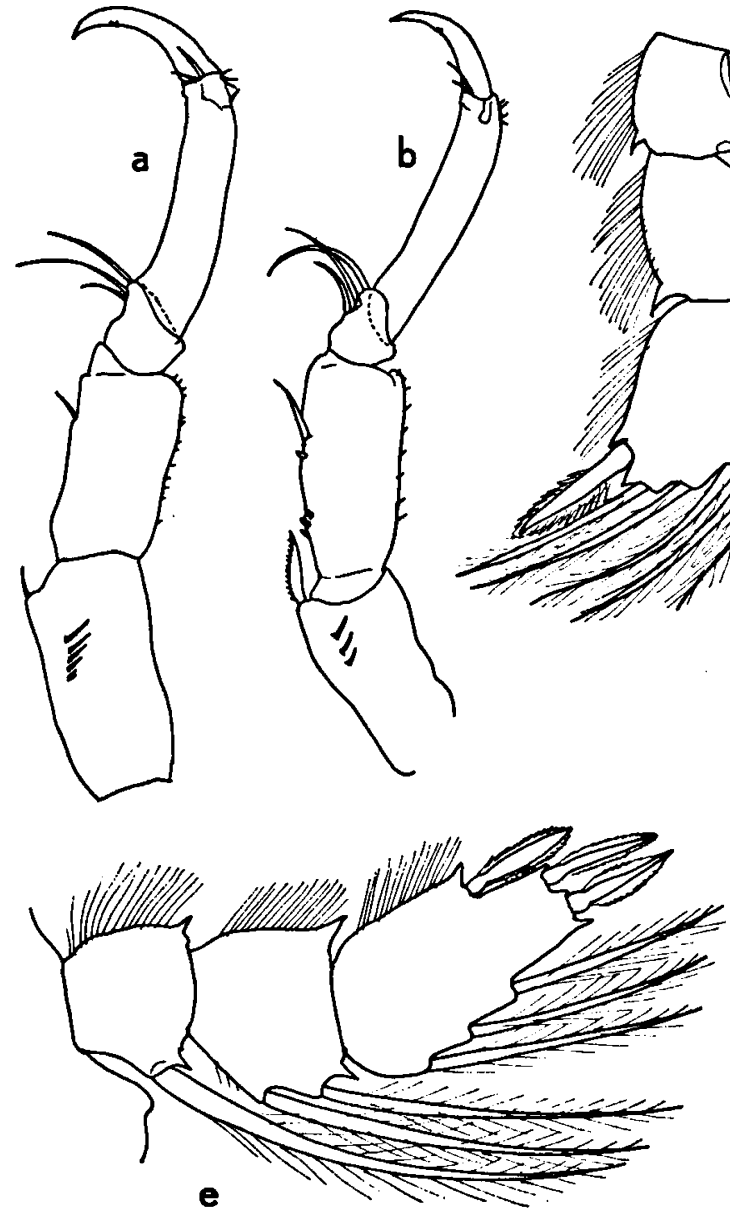

Fig. 14. Acanthomolgus muriceanus Humes, 1973 (paratypes from Bermuda). a, A2 ㅇ (scale C); b, A2 ô (C);
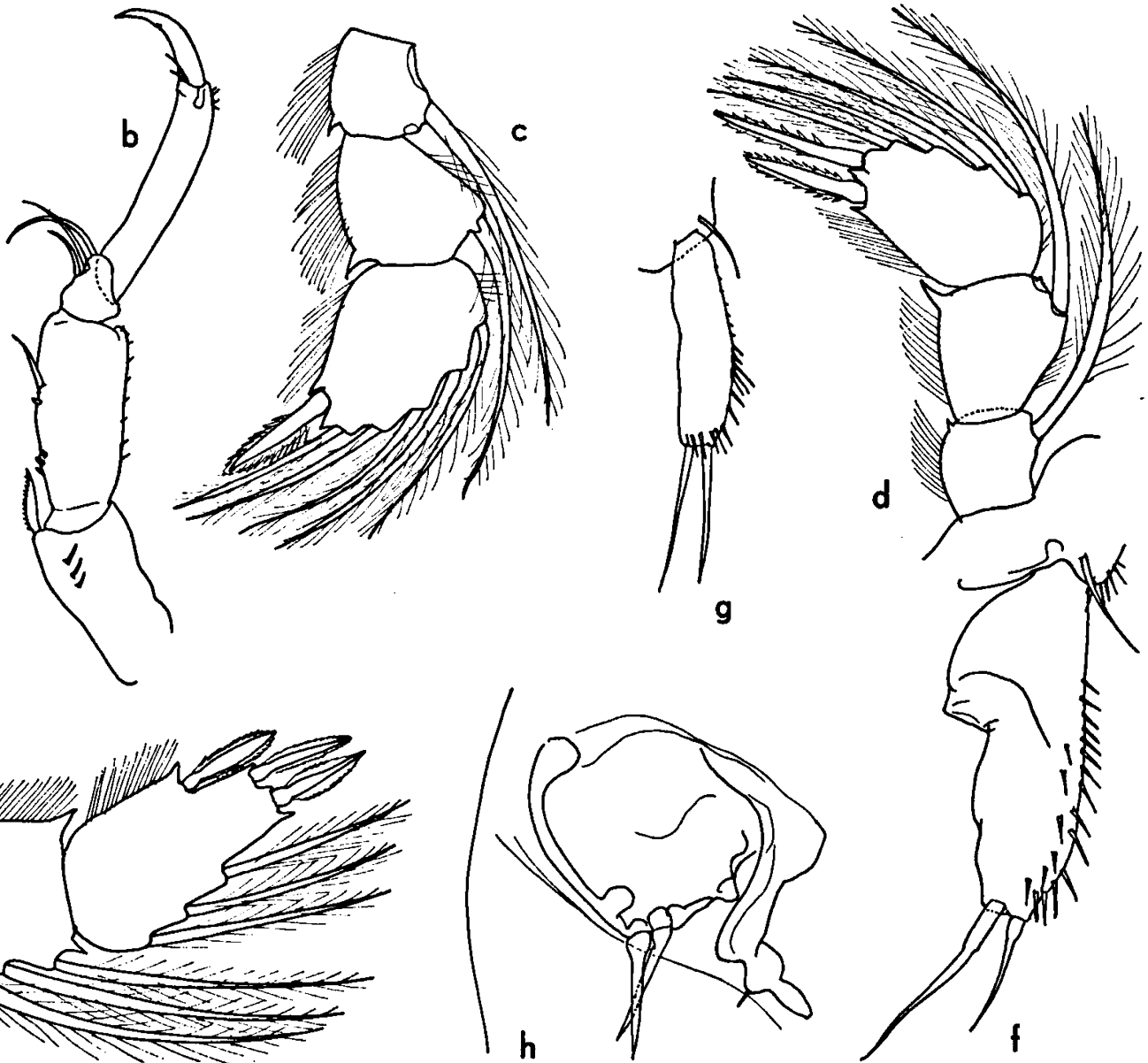

h

c, P1 $\&$, end. (B); d, P1 $\hat{\delta}$, end. (B); e, P2 $\hat{o}$, end. (B); f, P5 $\&$ (B); g, P5 of (B); h, genital area, + , dorsal (D). 

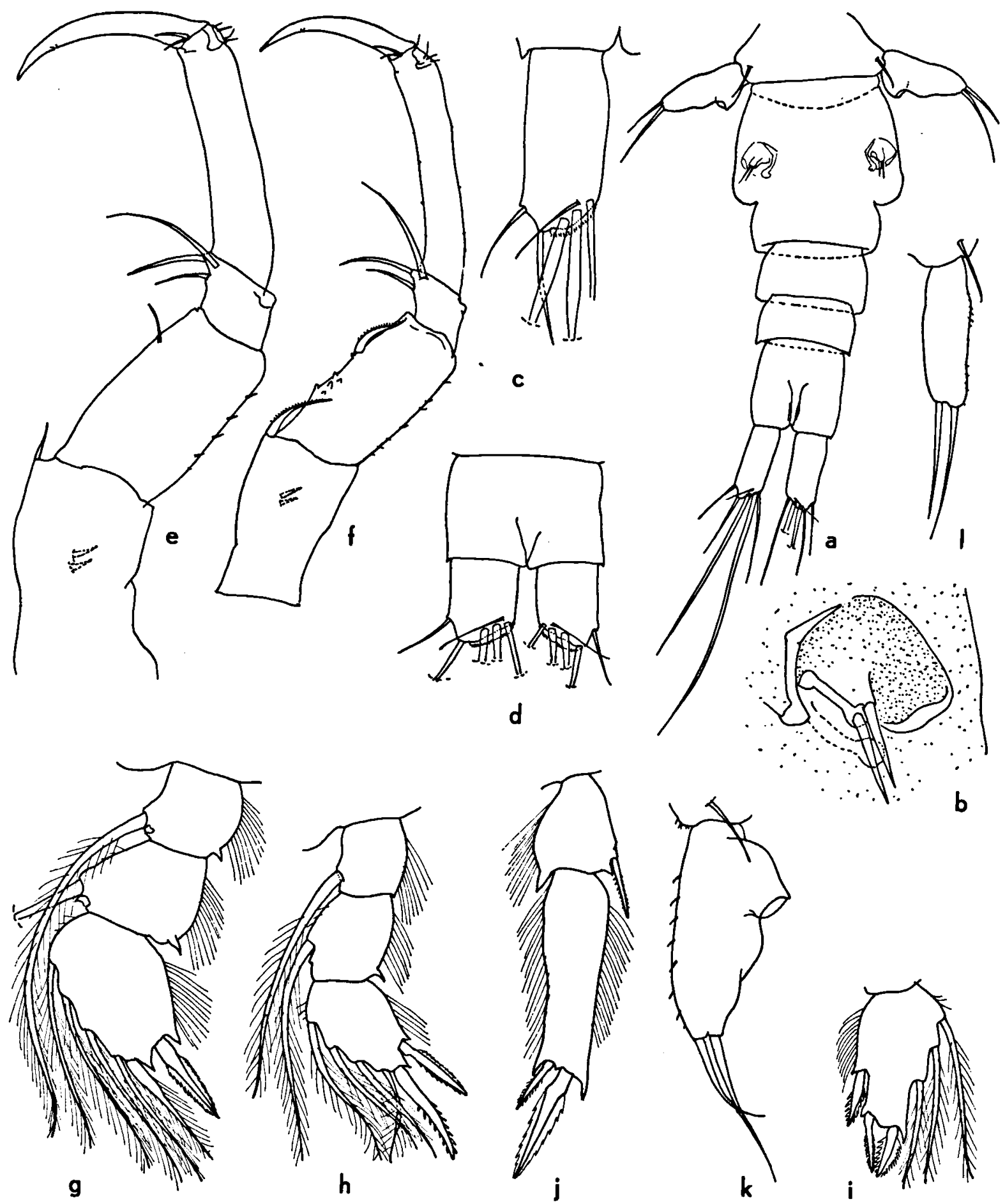

Fig. 15. Acanthomolgus longifurca n. sp. (paratypes from Curaçao). a, urosome, $\&$, dorsal (scale E); b, genital area, \%, dorsal (D); c, Fu. $\$$, dorsal (B); d, anal somite and

Fu. o, dorsal (B); e, A2 \& (B); f, A2 \& (B); g, P1 \&, end. (B); h, P1 $\delta$, end. (B); $i, P 2$ $\hat{\delta}$, end. 3 (B); j, P4 $\%$, end. (B); $\mathrm{k}, \mathrm{P5}$ \% (B); $1, \mathrm{P5} \hat{\delta}$ (D). 
Description. -

F e m a le : Body shape very similar to that of A. bayeri (cf. Humes, 1973, fig. 57). Length of the body 851-1036 $\mu \mathrm{m}$ (mean, based on 5 specimens, $905 \mu \mathrm{m})$; greatest width of cephalosome $382-432$ $\mu \mathrm{m}$ (mean $399 \mu \mathrm{m}$ ).

The genital somite (fig. 15a) is $142 \mu \mathrm{m}$ long and $153 \mu \mathrm{m}$ wide. The genital area (fig. 15b) has an imperfectly developed triangular process on the caudal sclerite, and no tubercle or spinule on the medial sclerite. The anal somite is $79 \mu \mathrm{m}$ long and $80 \mu \mathrm{m}$ wide. The Fu. (fig. 15c) is $66 \times 29 \mu \mathrm{m}$ (2.32 times as long as wide). All furcal setae are naked.

The A1 resembles that of $A$. muriceanus; the lengths of the articles, measured along the posterior margin, are $25,78,20,33,38,30$, and $27 \mu \mathrm{m}$; the length of article 1 , along its anterior margin, is $56 \mu \mathrm{m}$.

The A2 (fig. 15e) bears 2 spinules and a short distal seta on the basal article. Artiole 2 is $62 \mu \mathrm{m}$ long (allong the outer margin), and $38 \mu \mathrm{m}$ wide; the outer margin bears a few spinules; the inner margin a short subdistal seta. Article 4 is devoid of rows of spinules, it is $90 \mu \mathrm{m}$ long along the outer margin, $71 \mu \mathrm{m}$ allong the inner margin, and $18 \mu \mathrm{m}$ wide; the outer, subdistal armature consists of 4 minute setules, the distal armature of 1 claw (58 $\mu \mathrm{m}$ long allong the axis) and 2 small setiform elements.

The Md. and $\mathrm{Mxl}$ are as in $A$. muriceanus.

The $\mathrm{Mx} 2$ is likewise as in $A$. muriceanus, i.e. the lash is armed in its proximal part with smaller teeth than in its central part.

The Mxp. bears a slender distal endite, like in A. muriceanus, and is provided with 2 very unequal elements on article 2.

P1: the basp., coxp., and exp. resemble those of $A$. muriceanus, the end. (fig. $15 \mathrm{~g}$ ) is provided with rather long spiniform processes, and with a terminal spine which is hardly shorter than the next seta.

$\mathrm{P} 2, \mathrm{P} 3$, and $\mathrm{P} 4$ as in $A$. muriceanus, although P4 has long distal spiniform processes on end. 2 (fig. 15j).

P5 (fig. 15k) is $77 \mu \mathrm{m}$ long, and has a greatest diameter of $39 \mu \mathrm{m}$; the outer margin bears 6 to 8 small spinules of 4-5 $\mu \mathrm{m}$ long; the 2 naked distal setae are of unequal length. The inner margin bears a strong proximal expansion, and is undulated more distally.

M a le : General shape as in $A$. bayeri (of. Humes, 1973, fig. 73). Body length 656-670 $\mu \mathrm{m}$ (mean, based on 5 specimens, $660 \mu \mathrm{m})$; greatest width of cephalosome 250-273 $\mu \mathrm{m}$ (mean $264 \mu \mathrm{m}$ ). Genital somite $132 \mu \mathrm{m}$ wide and $127 \mu \mathrm{m}$ long. Anal somite (fig. 15d) $57 \mu \mathrm{m}$ wide and $42 \mu \mathrm{m}$ long. Fu. (fig. 15d) $27 \mu \mathrm{m}$ long and $23 \mu \mathrm{m}$ wide (length/width ratio $1.18: 1$ ); all furcal setae are naked.

The lengths of the articles of $\mathrm{Al}$ are (allong the postenior margin): $20,60,15,29,33,25$, and $27 \mu \mathrm{m}$; anticle 1 is, along the anterior margin, 41 $\mu \mathrm{m}$ long.

The A2 (fig. 15f) bears 2 spinules on the first artiole; the distal element on this article is transformed (dagger-like, curved, inner margin finely spinulose), llike the medioterminal element on article 2. Article 2 bears moreover a number of "wants" proximally of the transformed element. Article 3 has the same armature as in the female. Article 2 is $52 \mu \mathrm{m}$ long (along the outer margin) and $28 \mu \mathrm{m}$ wide; anticle 4 is $68 \mu \mathrm{m}$ long (along the inner margin) or $82 \mu \mathrm{m}$ (along the outer margin), and $13 \mu \mathrm{m}$ wide; the claw is $45 \mu \mathrm{m}$ long (along the axis).

The mouth parts are as in the female.

The Mxp. is resembling that of $A$. muriceanus.

P1 has a sexually dimorphous end. (fig. 15h): article 2 is more elongated and more rectangular in shape than in $\%$, and its medial seta is implanted more proximad than in $q$; end. 3 bears 2 spines, the lateral one being finely barbed, the other coarsely; the latter spine is as long as the next seta.

P2 has a sexually dimonphous end. 3 (fig. 15i) with 3 finely barbed spines, the centralmost of which is thinner than the others.

P3 and P4 as in the female.

P5 (fig. 151) is $28 \times 10 \mu \mathrm{m}$; the outer margin bears a row of minute spinules; the 2 terminal setae are naked and not much different in length.

Live colour. - Not noted.

Remarks. -

The present species has slender caudal rami in the female (hence the proposed specific name, longifurca). There are only four other species in the mononyx-group that have a $\mathrm{Fu}$. $q$ which is more than twice as Jong as wide: $A$. affinis, $A$. muriceanus, $A$. bayeri, and $A$. mononyx. The first two have long, conspicuous spinules on the outer margin of P5 $\left(9 \delta^{7}\right)$, the last one (mononyx) has this margin unarmed, whereas in the present species it bears minute spinules, like in $A$. bayeri.

From $A$. mononyx, the present species differs in several other characters as well (shape of P5 o with inner swelling; distal setae of P5 $q$ un- 
equal in length; 4th article of A2 $q \sigma^{*}$ elongate, etc.). The resemblance to muriceanus, affinis, and especially to bayeri is much greater.

In the length of the claw of $\mathrm{A} 2\left(\delta^{\circ}\right)$, the present species resembles $A$. affinis. It differs from affinis in (1) the length/width ratio of the Fu. $\sigma^{*}$ (longifurca 1.2-1.3, affinis 1.4-1.5); (2) in the length/width ratio of the P5 $\delta^{x}$ (longifurca $\leqslant 3$, affinis 4.6); (3) in a less strongly sexually dimorphous end. 3 of P1; (4) in the absence of a triangular process in the genital area ( $q)$; and (5) in the presence of minute spinules only, on the outer margin of $\mathrm{P} 5\left(\right.$ ( $\left.9 \sigma^{\circ}\right)$.

From $A$. muriceanus, the present species differs in the characters (1), (2), (4), and (5) of the enumeration in the preceding paragraph (in muriceanus: Fu. $\sigma^{\pi}$ 1.7-1.8 $\times$ as long as wide; P5 $\sigma^{\pi} 3.6$ $X$ as long as wide). Moreover, the A2 claw ( $9 \sigma^{\circ}$ ) is propontionally shorter in muriceanus.

From $A$. bayeri finally, the present species differs in the P5 $\sigma^{7}(>4$ times as long as wide in bayeri, < 3 times in longifurca); in the shorter claw on A2 ( $\left.9 \sigma^{\top}\right)$; in the different length/width ratio of $\mathrm{Fu} . \sigma^{*}$ (1.5 in bayeri, 1.2-1.3 in longifurca); in the mutual lengths of the distal setae of P5 $\sigma^{*}$ (subequal in longifurca, very unequal in bayeri); in the lower number of spinules on the outer margin of P5 $\&(<10$ in longifurca, $>15$ in bayeri); in the different length/width ratio of P5 o (length about twice the greatest width in tongifurca, 2.6 thimes in bayeri); in the slenderness of the endite of the Mxp. $q$ (endite spiniform in longifurca, triangular in bayeri).

\section{Acanthomolgus longidactylus n. sp. Figs. 16-17.}

Material examined. -

All on the octocoral Plexaura flexuosa.

Curaçao: Jan Thiel Bay, outside the jetty of the swimming pool; 11 \&, $4 \hat{\delta}, 1$ copepodid (of which 1 \% holotype, $1 \delta$ allotype, the remaining specimens paratypes); depth about $3 \mathrm{~m}$; Feb. 28, 1974 (ZMA coll. no. Co. 102,564 a-c).

Curaçao: Blauw Bay; 2 \&, 1 o ; depth about $3 \mathrm{~m}$; Oct. $17,1958$.

\section{Description. -}

Very close to several other members of the muriceanus-complex. Female (fig. 16a), length of the body $949-952 \mu \mathrm{m}$, greatest width of cephalosome 430-439 $\mu \mathrm{m}$. Male (fig. 16b), length of the body 707-727 $\mu \mathrm{m}$, greatest width of cephalosome 280 $292 \mu \mathrm{m}$.

The genital area $(q)$ has a small, roundedly triangular projection on the caudal sclerite (fig. $16 f)$.
The Fu. o (fig. $16 \mathrm{c}, \mathrm{d}$ ) is $52 \times 29 \mu \mathrm{m}$ (length/ width ratio $1.79: 1$ ); of the $\sigma^{\circ}$ (fig. 16e) it is $27 \times 20 \mu \mathrm{m}$ (ratio $1.30: 1$ ).

The following appendages are similar to those of $A$. muriceanus: A1 ( $\left.q \sigma^{x}\right), \mathrm{P} 2(q), \mathrm{P} 3\left(q \sigma^{x}\right)$, Mxp. $\sigma^{\circ}$.

The A1 (o) has 7 articles of the following lengths (measured along the posterior margin): 48 , $80,20,25,40,29$, and $33 \mu \mathrm{m}$; article 1 is $58 \mu \mathrm{m}$ long along the anterior margin. For A1 $\sigma^{x}$ these measurements are $36,78,19,32,41,30$, and 32 $\mu \mathrm{m}$ (article 1, anterior, is $52 \mu \mathrm{m}$ long).

The A2 9 (fig. 16k) has 2 spinules on article 1; articles 1 and 2 each have a short, setiform element on the inner surface; the outer margin of article 2 bears a row of minute spinules; article 2 is much less than twice as long as wide; it is 64 $\mu \mathrm{m}$ long along the outer margin. Article 4 is unarmed along the margins; it is $75 \mu \mathrm{m}$ long along the inner margin, $95 \mu \mathrm{m}$ along the outer margin, and $20 \mu \mathrm{m}$ wide. The terminal claw is $71 \mu \mathrm{m}$ long along its axis.

The A2 o' (fig. 161) has transformed, unilaterally barbelated, spines on articles 1 and 2; article 2 is less than twice as long as wide, 56-59 $\mu \mathrm{m}$ long; it bears some spinules on its outer margin; article 4 lacks such spinules. The most proximal claw-like seta on article 3 is slightly barbed. Article 4 is $73 \mu \mathrm{m}$ long along its inner margin, $91 \mu \mathrm{m}$ along its outer margin, and $18.5 \mu \mathrm{m}$ wide. The terminal claw is $71 \mu \mathrm{m}$ long along its axis.

The mouth parts (figs. $16 \mathrm{~g}, 16 \mathrm{~h}, 16 \mathrm{i}$ ) are built in a way similar to that in the other species. In the $\mathrm{Mx} 2$, the great length of the medial spine (at the base of the lash) is noteworthy. The auxiliary lash of the Mx2 bears 6 or 7 needle-like teeth at its medial margin, and 2 at its lateral mangin. The hyaline, toothed margin of the main lash is wide.

The Mxp. \& (fig. 16j) is distally structured as follows: a long, vaguely barbed spine, opposing a shorter, pointed endite; a setule, as long as the endite, arises at the base of the latter.

The P1 $q$ is similar to that of $A$. verrucipes (cf. Humes, 1973, fig. 43). P1 $\sigma^{*}$ bears 2 spines and 4 setae on end. 3 (fig. 17b); the terminalmost spine is rather coarsely toothed, but not so coarse as, for instance, in A. aequiseta. The entire Pl end. is transformed in comparison with that of the $q$, just as, for instance, in $A$. longifurca.

The P2 $\sigma^{\circ}$ bears a very long spiniform process on the medioterminal corner of end. 3 (fig. 17c), a situation similar to that in $\boldsymbol{A}$. gorgoniae and $\boldsymbol{A}$. bilobipes.

The P4 ( $\left.q \delta^{7}\right)$ (fig. 17a) is chiefly characterized 


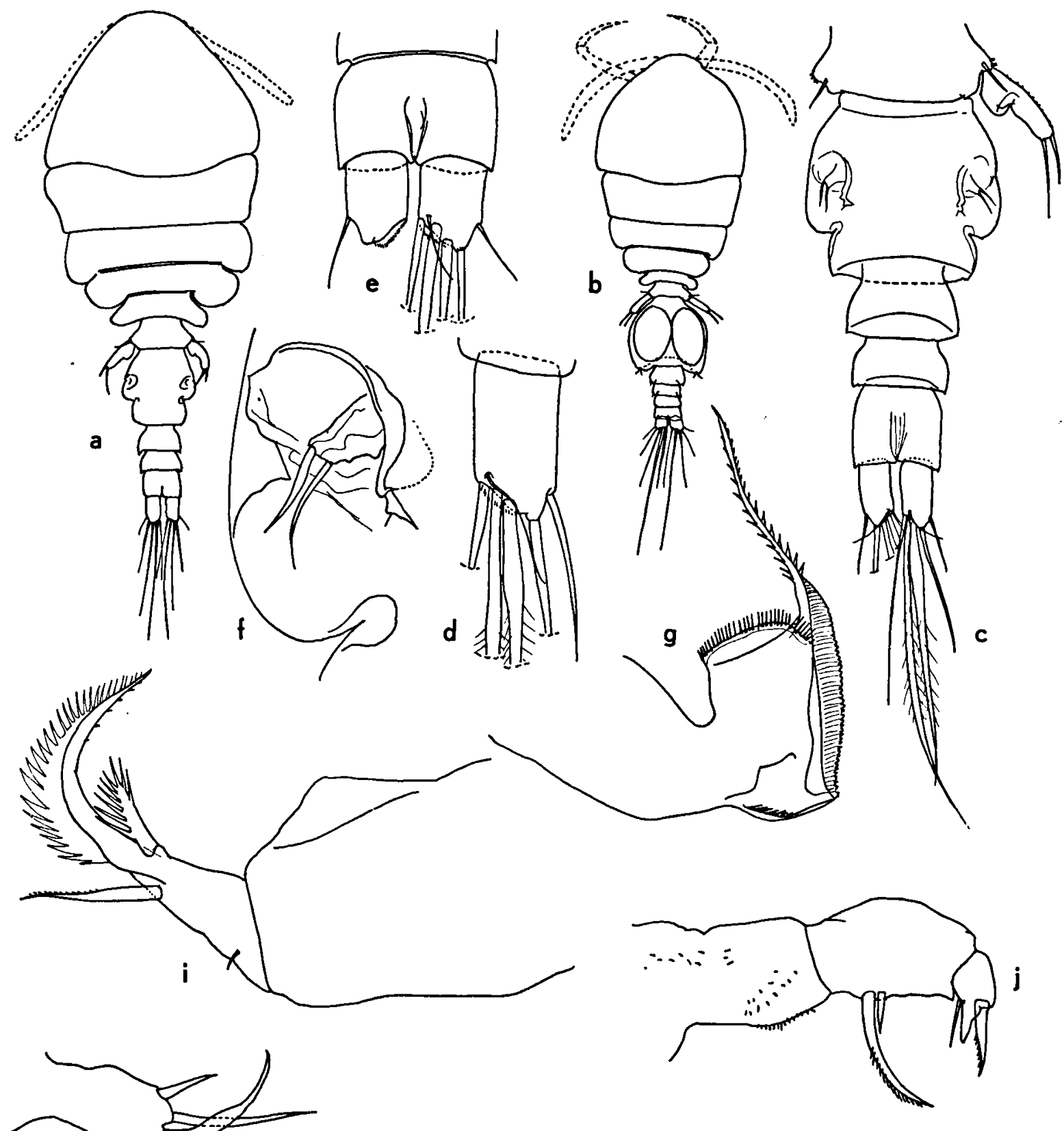

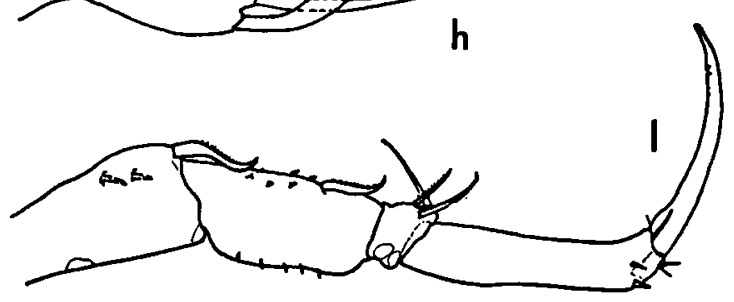

Fig. 16. Acanthomolgus longidactylus n. sp. (paratypes from Curaçao). a, \&, dorsal (scale A); b, ô, dorsal (A); c, urosome, \$, dorsal (E); d, Fu. \&, dorsal (B); e, anal

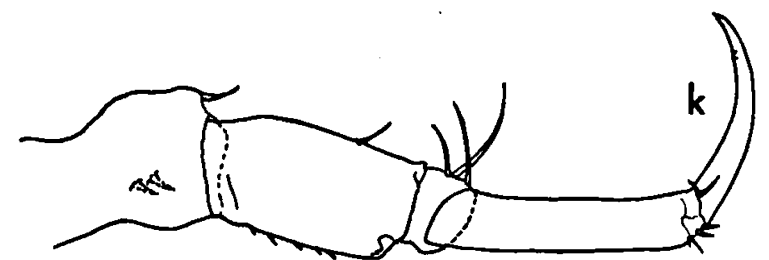

somite and Fu. $\delta$, dorsal (B); f, genital area, $\$$, dorsal (D); g, Md. \& (D); h, Mx1 \& (D); i, Mx2 \& (D); j, Mxp. ㅇ (B); k, A2 \& (C); l, A2 of (C). 
by a field of spinules on the lateral corner of the coxp., and by the presence of long plumosities on the outer seta of the basp. End. 2 with strong, pointed processes on the distolateral and distomedial corners; outer terminal spine weak.

P5 $q$ (fig. 17e) with a mediobasal swelling which is relatively smaller than in $A$. muriceanus. The outer margin bears a row of spinules of about $3 \mu \mathrm{m}$ long. The length of P5 is $72 \mu \mathrm{m}$, the greatest width is $28 \mu \mathrm{m}$; the distal diameter is $12 \mu \mathrm{m}$.

P5 $\sigma^{x}$ (fig. 17d) is not very slender $(29 \times 10$ $\mu \mathrm{m})$; its lateral margin is armed with minute spinules.

Colour of live spocimens. - Body opaque, whitish, vaguely grey-greenish, or vaguely yellowish; ovaries and ovisacs grey-green; eye bright red.

\section{Remarks. -}

The present species differs from $A$. muriceanus and $A$. affinis by having a longer claw (about as long as article 4 measured along its inner margin) on A2 ( $\left.q \sigma^{7}\right)$, by possessing only very small spinules on the lateral margin of P5 ( $\left.q \sigma^{\circ}\right)$, and by a smaller length/width ratio of the Fu. $\$$.

In many respects, $\boldsymbol{A}$. longidactylus is resembling $A$. verrucipes and $A$. bayeri, which both have a long A2 claw in combination with minute spinules on P5.

However, $A$. verrucipes has a row of spinules on the inner margin of article 4 of A2 $\sigma^{7}$ (lacking in longidactylus), but lacks a row of spinules on the outer margin of article 2 of A2 $q \sigma^{*}$ (present in longidactylus). Article 4 of $\mathrm{A} 2 \%$ is distinctly more slender in longidactylus than in verrucipes. The mediobasal swelling of $\mathrm{P} 5 \%$ is more confined to the basal part of the article in longidactylus. In P4 ( $\left.90^{+}\right)$the outer basipod seta is plumose in longidactylus, naked in verrucipes. The projections on the distal corners of P4 end. 2 $\left(q \delta^{7}\right)$ are much longer in longidactylus. The distall Mxp. structure $(q)$, viz. with the spine longer than the endite, characterizes longidactylus. The auxiliarly lash of $\mathrm{Mx} 2\left(9 \sigma^{\circ}\right)$ bears denticles on both margins in longidactylus, on the lateral margin only in verrucipes. The P5 $\sigma^{\circ}$ is less than 3 times as long as wide in longidactylus, and more than 5 times in verrucipes; it bears 2 subequal terminal setae in longidactylus (unequal in verrucipes). The very long medioterminal process on $\mathrm{P} 2$ end. 3 $\left(\sigma^{*}\right)$ is also distinctive for longidactylus.

$A$. bayeri has an A2 ( $\left.9 \sigma^{7}\right)$ and a P5 ( $\left.q\right)$ resembling the corresponding appendages of longidactylus. Differences are found in the P5 $\sigma^{*}$ (almost $4 \times$ as long as wide in bayeri, not yet $3 \times$ in longidactylus); in the Fu. $\&$ '(more than twice as long as wide in bayeri, less than twice in longidactylus); in the medial spine at the base of the main lash of $\mathrm{Mx} 2\left(\% \sigma^{*}\right)$ (long in longidactylus, short in bayeri); in the P4 $\left(9 \sigma^{\circ}\right)$, in the Mx2 $\left(q \sigma^{*}\right)$, in the Mxp. ( $q$ ), in the P2 $\left(\sigma^{*}\right)$, and P5

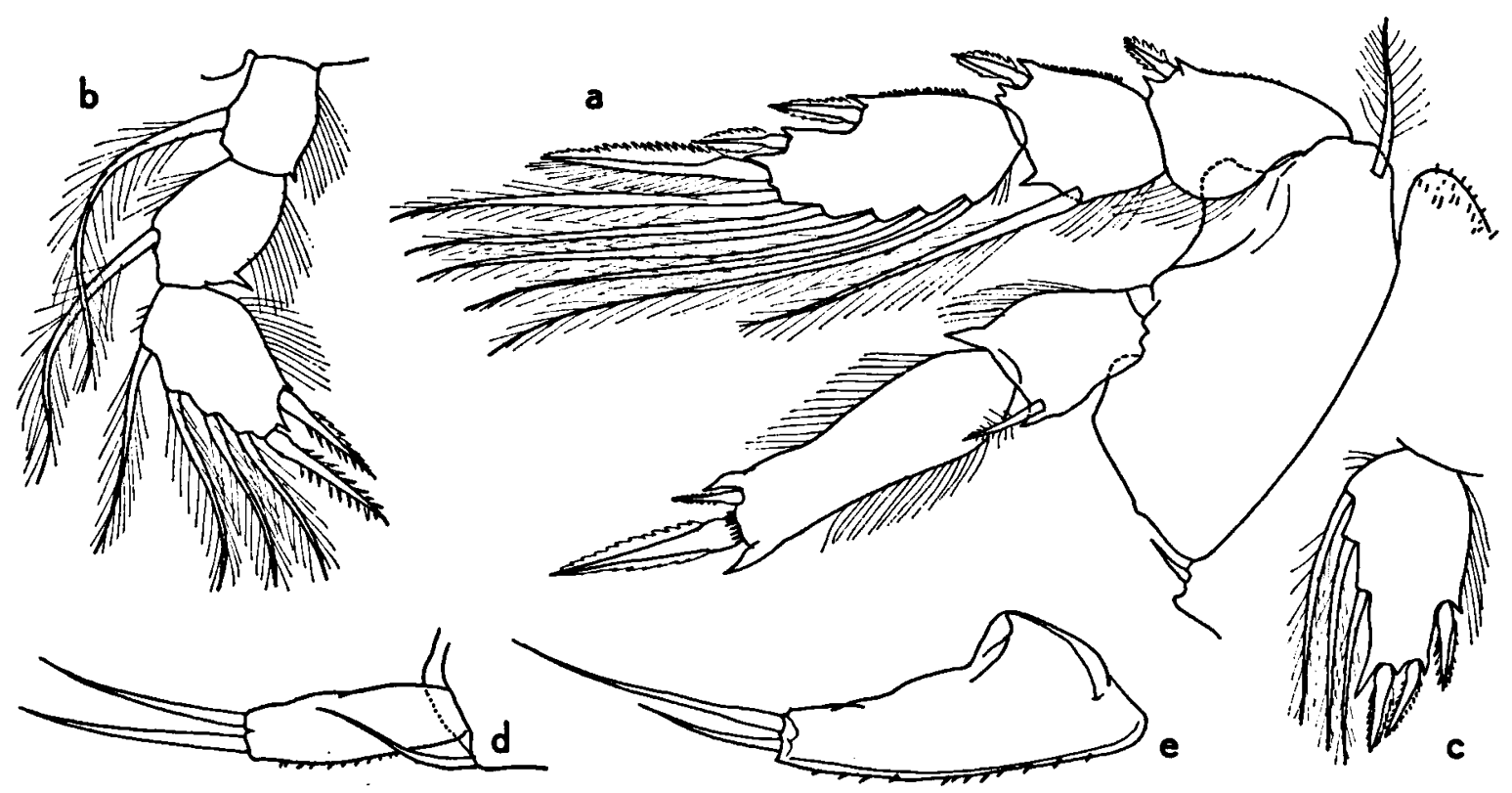

Fig. 17. Acanthomolgus longidactylus n. sp. (paratypes from Curaçao). a, P4 $\&$ (scale B); b, P1 $\hat{o}$, end. (B); c,

P2 ô, end. 3 (B); d, P5 ô (D); e, P5 \& (B). 
$\left(\sigma^{*}\right)$, longidactylus differs from bayeri just as it differs from verrucipes.
Etymology. -

The name longidactylus alludes to the long claw on the posterior antenna.

\section{REFERENCES}

Humes, A. G., 1973. Cyclopoid copepods of the genus Acanthomolgus (Lichomolgidae) associated with gorgonians in Bermuda. J. nat. Hist., $7: 85-115$, figs. $1-104$.

- , 1974. Cyclopoid copepods (Lichomolgidae) from gorgonaceans in Madagascar. Proc. biol. Soc. Wash., 87 (37) : 411-438, figs. $1-90$.
Humes, A. G. \& J. H. Stock, 1972. Preliminary notes on a revision of the Lichomolgidae, cyclopoid copepods mainly associated with marine invertebrates. Bull. zool. Mus. Univ. Amsterdam, 2 (12) : 121-133.

- \& - , 1973. A revision of the family Lichomolgidae Kossmann, 1877, cyclopoid copepods mainly associated with marine invertebrates. Smithson. Contr. Zool., 127 : $\mathrm{i}-\mathrm{v}, 1-368$, figs. $1-190$. 